\title{
Linearization of Thermal Equivalent Temperature Calculation for Fast Thermal Comfort Prediction
}

\author{
Christian Rommelfanger ${ }^{1, *}$, Louis Fischer ${ }^{1}{ }^{\mathbb{C}}$, Jérôme Frisch ${ }^{2} \mathbb{C}$ and Christoph Van Treeck ${ }^{2}$ \\ 1 Porsche AG, 71278 Weissach, Germany; Louis.Fischer1@porsche.de \\ 2 RWTH Aachen, 52062 Aachen, Germany; frisch@e3d.rwth-aachen.de (J.F.); \\ treeck@e3d.rwth-aachen.de (C.V.T.) \\ * Correspondence: Christian.Rommelfanger1@porsche.de
}

Citation: Rommelfanger, C.

Fischer, L.; Frisch, J.; Van Treeck, C. Linearization of Thermal Equivalent Temperature Calculation for Fast Thermal Comfort Prediction. Energies 2021, 14, 5922. https://doi.org/ 10.3390/en14185922

Academic Editor: Christopher Micallef

Received: 22 June 2021

Accepted: 13 September 2021

Published: 17 September 2021

Publisher's Note: MDPI stays neutral with regard to jurisdictional claims in published maps and institutional affiliations.

Copyright: (c) 2021 by the authors. Licensee MDPI, Basel, Switzerland. This article is an open access article distributed under the terms and conditions of the Creative Commons Attribution (CC BY) license (https:// creativecommons.org/licenses/by/ $4.0 /)$.

\begin{abstract}
Virtual simulations and calculations are a key technology for future development methods. A variety of tools and methods for calculating thermal comfort have not gained sufficient acceptance in practice due to their inherent complexity. This article investigates alternative means of determining thermal comfort, namely, the linearization of the equivalent temperature calculation. This enables a wide range of users to evaluate thermal comfort in a fast and easy manner, for example, for energy efficiency simulation. A flow and thermal model were created according to the requirements of DIN EN ISO 14505 to determine heat transfer coefficients under calibration conditions. The model to simulate the equivalent temperature in calibration conditions comprises a geometrically realistic $3 \mathrm{D}$ model of a human test person according to the standard. The influence of the turbulence model, as well as the influence of the equivalent temperature on the heat transfer coefficient in calibration conditions, was investigated. It was found that the dependence of the equivalent temperature is mandatory. The dependence between the heat transfer and the equivalent temperature was taken into account with a continuous linearization approach. An equation-based implementation methodology is proposed, enabling a quick implementation of comfort evaluation in future simulation models. Two test cases show the capabilities of the new model and its application in future work.
\end{abstract}

Keywords: thermal comfort; simulation; heat transfer; numerical fluid simulation

\section{Introduction}

Virtual development tools will significantly change engineering methods in the next few years. Simulations will not only shorten development cycles but also reduce development costs. In many areas, a simulation-based approach is already replacing experimentation, and the proportion of simulations will continuously increase. However, the sub-discipline of technical calculation should not only be enhanced in the field of simulation techniques but also in the area of post-processing. Subjective sensations from the field of ergonomics, such as thermal comfort, still require physical testing for evaluation in many places today. Although efforts are being made in many areas to derive thermal comfort from measurable variables, this approach has not yet been fully established in the simulation-based development process of the industry. The approach of equivalent temperature $\left(T_{e q}\right)$ for thermal comfort evaluation defined in the standard DIN EN ISO 14505 offers a comprehensible way of achieving this. However, recent publications such as Voelker [1] and Streblow [2] only show an evaluation for a few discrete ambient temperatures and a rather complex iterative calculation for the heat transfer coefficients (heq). In contrast, a continuous evaluation of the equivalent temperature is mandatory for real-world applications, e.g., in car interiors with many possible air temperatures. The approach described in this paper aims to simplify the heq calculation by linearization with a negligible loss in accuracy to allow for a fast thermal comfort evaluation using the concept of equivalent temperature, applicable for arbitrary real-world ambient conditions. 


\subsection{Related Work}

\subsubsection{General Thermal Comfort Prediction}

According to the ASHRAE-55 [3], thermal comfort is the subjective mental state that expresses satisfaction with the thermal environment. The first correlation between thermal sensation votes of people in relation to the energy balance of their bodies was completed by Fanger [4]. He introduced the predicted mean vote (PMV) and the percentage of people being dissatisfied (PPD). Both indices describe thermal comfort for the body as a whole and not locally for the single body parts such as the arms, torso, head, or legs. Very often, non-uniform or asymmetrical effects are from interest, which will not be captured by the PMV or PPD model. For the prediction of non-uniform thermal comfort, the equivalent temperature concept is used. With the DIN EN ISO 14505 [5], a method exists for expressing thermal comfort in a simple way as a function of the equivalent temperature.

\subsubsection{The DIN EN ISO 14505}

The DIN EN ISO 14505 is based on the calculation and assessment of the equivalent temperature. The equivalent temperature is a physical temperature quantity based on the dry heat exchange of the human body. It combines the effects of convection and radiation on the heat exchange of the human body. The climate conditions are assessed in terms of local effects on specific parts of the body. The local equivalent temperatures determine the degree to which the relevant parts of the body parts are within acceptable levels of heat loss. The equivalent temperature allows a quantitative assessment of the heat exchange. Higher $T_{e q}$ values indicate lower heat losses, whereas lower $T_{e q}$ values indicate higher heat losses. The relationship between local $T_{e q}$ values for 16 body segments and the perceived thermal sensation was determined with measurements on subjects subjected to $1 \mathrm{~h}$ of a variety of thermal conditions. The necessary link between measurement, calculated $T_{\text {eq }}$, and the subjective thermal sensation is then completed by thermal comfort diagrams. The underlying measurements in the DIN EN ISO 14505 are widely accepted in the scientific context; therefore, this work will focus on the calculation of the equivalent temperature and use the underlying data from the DIN EN ISO 14505 as validation. The calculation of the local equivalent temperature is mainly based on the work of Nilsson [6,7]. Nilsson proposed characterizing the thermal comfort by the heat transfer coefficients at the body. For this purpose, he compared test person studies with measurements and simulations to describe thermal comfort.

1.1.3. Related Work Regarding Equivalent Temperature Calculation and the Application of $T_{\text {eq }}$ Calculation

To improve the methodology further with respect to the thermal physiology of the human body, the Fiala model is often used in current research [8]. In addition, other authors and Fiala himself have also worked with nodal networks to calculate thermal physiology [9-16]. Several authors use the relation from Nilsson to calculate the thermal comfort for all kinds of applications, such as in buildings, aircraft, and transportation [17-20]. Wölki et al. [21] have even used the method as a control target value for thermal comfort. Other authors focused on another influence on thermal comfort-namely, the contact resistance between surfaces and the skin [22-24].

\subsubsection{Further Development Regarding Heat Transfer and Influence on Heat Transfer}

However, the equations for the thermal comfort currently used by many authors are based on the geometry of Nilsson's thermal manikin. The manikin consisted of rectangular blocks, so there is a major geometrical difference to real human body parts and, therefore, their heat transfer coefficients. Taghinia [25] studied the effect of simplification in relation to heat transfer but not in relation to thermal comfort. A study by Yousaf investigated the influence of the k-omega SST and Standard k-epsilon turbulence model on the flow field around a female manikin [26]. According to Lee et al. [27], turbulence intensity plays a major role in regard to the heat transfer at an airspeed above $0.3 \mathrm{~m} / \mathrm{s}$, but they did not put 
their results into perspective with thermal comfort. A similar study from Voelker et al. [1] with a coupling approach was completed on the full body and not for single body parts. Gao et al. [28] made a study on the heat transfer regression for single body parts at sitting and standing positions for a female body without a regression for the heat transfer in calibration conditions itself. Other influences such as the difference with respect to the clothing factor, but setting the convective and radiative heat transfer coefficient as a constant was investigated by several authors [29-31]. Streblow and Voelker accounted for the dependence of heat transfer coefficient in regard to the equivalent temperature in calibration conditions for discrete $T_{e q}$, but not for a continuous $T_{e q}[1,2]$. The author could not find investigations about the influence of the turbulence model in regard to the thermal comfort of a manikin. With the thermal resistance network between the skin, clothing, and surrounding air in mind, the convective and radiative thermal resistance will be important at low air velocities and the clothing factor for higher velocities. The aim of the present work is to linearize the equivalent temperature calculation to resolve the dependency between the heat transfer coefficient and the equivalent temperature to make the approach closer to the real-world behavior for low velocities. Furthermore, all of the previous studies share the necessity to implement the calculation of the thermal comfort in a rather complex manner to predict the local thermal comfort [2].

\subsubsection{Further Development Regarding Calculation Effort}

Similar work to reduce the calculation effort for the heat transfer coefficients in real conditions has been completed by several authors in different applications but not in the context of equivalent heat transfer calculation [32,33]. Table 1 gives an overview of the works that are most closely related.

Table 1. Literature overview.

\begin{tabular}{|c|c|c|c|c|c|c|c|c|}
\hline & 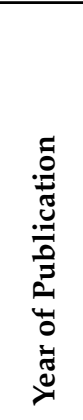 & 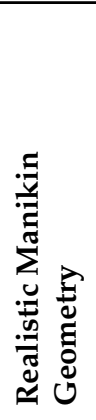 & 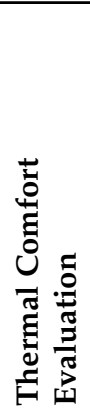 & 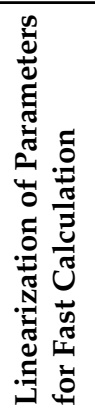 & 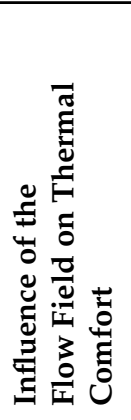 & 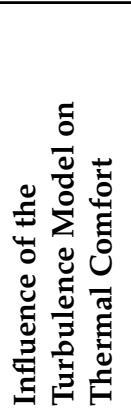 & 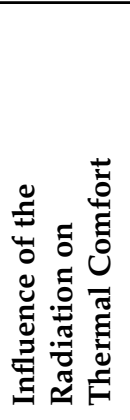 & 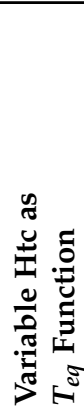 \\
\hline Taghinia [25] & 2018 & $x$ & & $x$ & & & & \\
\hline Lee et al. [27] & 1991 & & $\mathbf{x}$ & & $x$ & & & \\
\hline Voelker et al. [1] & 2018 & $\mathbf{x}$ & $\mathbf{x}$ & & & & & $\mathbf{x}$ \\
\hline Gao et al. [28] & 2019 & $x$ & & & $\mathbf{x}$ & & $\mathbf{x}$ & \\
\hline Ozeki et al. [29] & 2019 & $\mathbf{x}$ & $x$ & & $\mathbf{x}$ & $\mathbf{x}$ & & \\
\hline Morishita et al. [31] & 2018 & $x$ & $x$ & & $\mathbf{x}$ & & $\mathbf{x}$ & \\
\hline Streblow et al. [2] & 2011 & $x$ & $x$ & $\mathbf{x}$ & & & & $\mathbf{x}$ \\
\hline Yousaf et al. [26] & 2011 & $x$ & & & & $x$ & & \\
\hline
\end{tabular}

The remainder of the paper is structured as follows: Section 3 highlights the simulation models and gives an overview of the topic before concluding in Section 4, describing the linearization procedure. Section 5 gives some application examples as well as validation and performance benchmarks of the model. 


\section{Simulation Models}

The calculation of the equivalent temperature is based on the basic assumption that the heat flow between body parts and the environment in real conditions corresponds to the heat flow in homogenous calibration conditions of a uniform enclosure. The wall temperature of this respective enclosure under these uniform (calibrated) conditions is called equivalent temperature. Comfort diagrams for each segment of the body map the equivalent temperatures to a subjective thermal comfort vote. The correlation between subjective votes and equivalent temperature is evaluated by subject testing under welldefined personal (clothing insulation, metabolic activity, etc.) and climatic test conditions.

The projection between the real conditions and the calibration conditions is realized by evaluating the heat transfer coefficient $h_{e q}$, defined in calibration conditions as

$$
h_{e q}=\frac{\dot{Q}_{e q}}{T_{s}-T_{e q}}\left[\frac{\mathrm{W}}{\mathrm{K}}\right]
$$

with respect to the heat flow $\dot{Q}_{e q}$, temperature in calibration conditions $T_{e q}$, and the skin temperature $T_{\mathrm{s}}$.

For a constant skin temperature, emission factors, and inflow velocity, the emitted heat flow

$$
\dot{Q}_{e q}=f\left(T_{e q}\right)
$$

is only dependent on the temperature of the calibration conditions.

Thus, the heat transfer coefficient in calibration conditions

$$
h_{e q}=f_{h e q}\left(\dot{Q}_{e q}\left(T_{e q}\right), T_{e q}\right)=f_{h e q}\left(T_{e q}\right) .
$$

is only dependent on the equivalent temperature.

In order to calculate the equivalent temperature in real conditions, the heat flow in working conditions

$$
\dot{Q}_{\text {real }}=\dot{Q}_{e q}=\dot{Q}
$$

must correspond to that in equivalent conditions.

Equation (1) can be solved using Equations (3) and (4) according to the equivalent temperature to

$$
T_{e q}=T_{s}-\frac{\dot{Q}_{\text {real }}}{h_{\text {eq }}}=T_{s}-\frac{\dot{Q}}{f_{\text {heq }}\left(T_{\text {eq }}\right)}
$$

The calculated equivalent temperature is inserted into the DIN EN ISO 14505 comfort diagrams, and the thermal comfort can be assessed from the resulting diagram.

\subsection{Numerical Fluid Dynamics Model}

For the determination of the heat transfer resistances in calibration conditions, thermal fluid flow simulations are used according to the standard DIN EN ISO 14505 [5]. The continuity equation results from observations on an infinitesimal control volume $d V$ with the velocity $v$ and the density $\rho$

$$
\frac{\partial}{\partial t} \int_{V} \rho d V+\oint_{A} \rho v d a=0
$$

The momentum conservation in integral form for the fluid is given with the identity tensor $I$, the pressure $p$, the viscous stress tensor $T$, and body forces $f_{b}$ as [34]

$$
\frac{\partial}{\partial t} \int_{V} \rho v d V+\oint_{A} \rho v * v d a=-\oint_{A} p I * d a+\oint_{A} T d a+\int_{V} f_{b} d V
$$


The energy conservation of the infinitesimal volume element for the total energy per unit mass $E$ can be written under consideration of the Fourier heat conduction and a source term, as [34]

$$
\frac{\partial}{\partial t} \int_{V} \rho E d V+\oint_{A} \rho H v d a=-\oint_{A} q d a+\oint_{A} T v d a+\int_{V} f_{b} v d V
$$

Modeling the medium as an ideal gas allows for the consideration of the influence of pressure and temperature on the air density [34]

$$
\rho=\frac{p}{R \cdot T}
$$

to consider the buoyancy effects in the flow field.

The mass, momentum, and energy conservation equations result in a non-linear equation system, the Navier-Stokes equations. The equations are solved numerically with second-order upwind discretization on a grid with polyhedron elements. Due to the strong coupling between velocity and temperature field, the equations have to be solved by an implicitly coupled approach.

The surface-to-surface radiation is calculated by ray tracing using the enclosure theory with view factors. The radiation power $P_{1-2}$ from one surface patch $d S_{1}$ to another $d S_{2}$ is

$$
P_{1-2}=i_{1}^{\prime} d S_{1} \cos \left(\AA_{1}\right)\left(\frac{d S_{2} \cos \left(\aleph_{2}\right)}{L^{2}}\right)
$$

where $\beta$ is the angle between the surface normal and a line between the two surfaces, and the length $L$ of this line. The total intensity $i_{1}^{\prime}$ is defined as the radiative energy passing through an area per unit solid angle, per unit of the area projected normal to the direction of passage, and per unit of time.

The view factor $F$ is defined as the ratio of the total radiation emitted by patch 1 to the radiation received by patch 2

$$
F_{1-2}=\frac{P_{1 \_2}}{P_{1, \text { total }}} \text {. }
$$

The calculation of the view factor $F_{1-2}$ between the surfaces is based on the topological conditions and is calculated by

$$
F_{1-2}=\frac{1}{S_{1}} \int_{S_{1}} \int_{S_{2}} \frac{\cos \left(\Re_{1}\right) \cdot \cos \left(\S_{2}\right)}{\pi \cdot L^{2}} d S_{1} \cdot d S_{2}
$$

The approximation of the integral is completed by ray tracing, where each patch sends out a specified number of beams at a discretized hemisphere over the patch.

The view factors are calculated once in the initialization phase. During the calculation, the heat exchange is iteratively calculated based on the view factor matrix, assuming a radiative equilibrium. The heat flow exchanged by radiation is used as a boundary condition on the faces. For more details on the solving approach, see [35] or [36].

The equivalent heat transfer coefficient $h_{e q}$, defined in Equation (13), is based on the total exchanged heat flow, incorporating the sum of convection, conduction in the thermal boundary layer, and radiation. The reference temperature for the heat transfer coefficient is the equivalent temperature, i.e., the wall temperature of the room.

$$
h_{e q}=\frac{\dot{Q}_{s}}{T_{s}-T_{e q}}
$$

\subsection{Structure of the Simulation Model}

The manikin geometry resembles a 95-percentile male RAMSIS model geometry and is geometrically processed as a solid body [37]. 
The subdivision of the body areas was carried out as suggested by Nilsson, corresponding to the comfort diagrams in DIN EN ISO 14505 [4,5], see Table 2.

Table 2. Body Segments assignment by index, letter, and name.

\begin{tabular}{lll}
\hline Index & Letter & Name \\
\hline 1 & a & Foot Right \\
\hline 2 & b & Foot Left \\
\hline 3 & c & Calf Right \\
\hline 4 & d & Calf Left \\
\hline 5 & e & Thigh Right \\
\hline 6 & f & Thigh Left \\
\hline 7 & g & Hand Right \\
\hline 8 & h & Hand Left \\
\hline 9 & i & Lower Arm Right \\
\hline 10 & j & Lower Arm Left \\
\hline 11 & k & Upper Arm Right \\
\hline 12 & l & Upper Arm Left \\
\hline 13 & m & Upper Back \\
\hline 14 & n & Chest \\
\hline 15 & o & Face \\
\hline 16 & p & Scalp \\
\hline 17 & q & Torso \\
\hline 18 & $\mathrm{x}$ & Whole Body \\
\hline
\end{tabular}

The grid independence of the mesh was investigated with a study of four different base sizes, using the total heat flux of the body as an indicator for independence; see Figure 1.

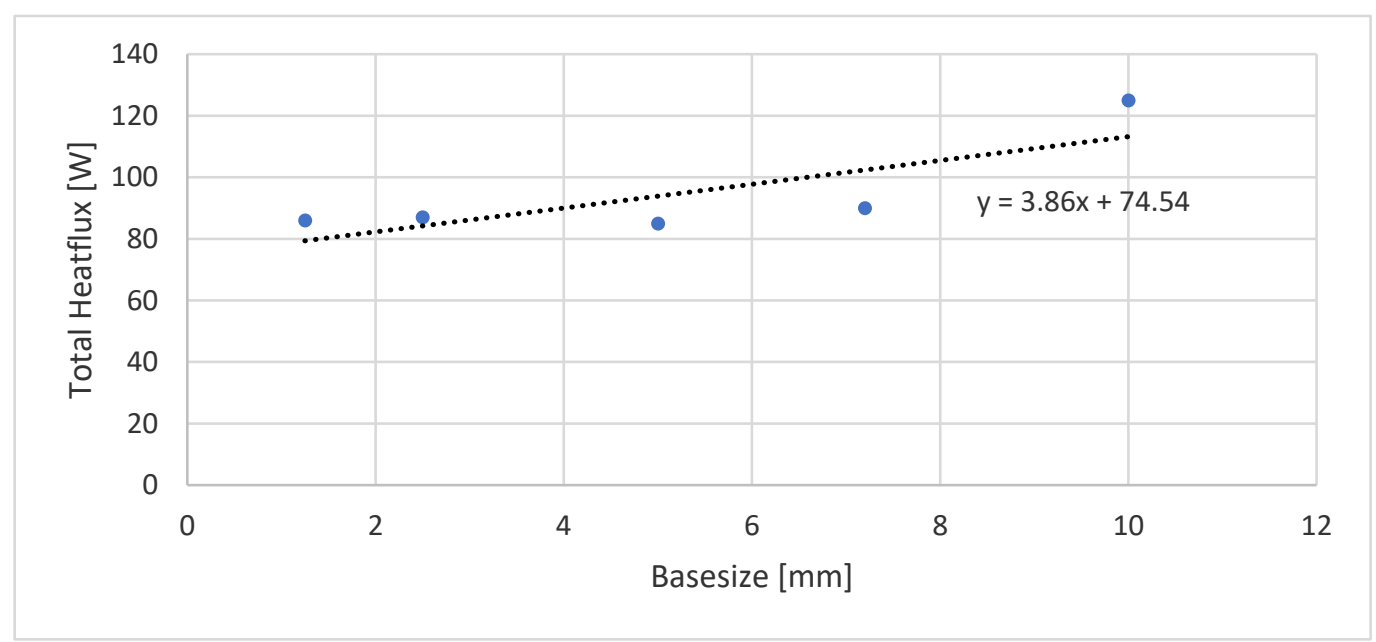

Figure 1. Grid independence for the mesh.

The surface of the body is meshed with a base size of $5 \mathrm{~mm}$ polyhedron elements. The volume mesh uses a growth factor of 1.2 until reaching $30 \mathrm{~mm}$ in $2 \mathrm{~m}$ distance to the RAMSIS. To account for realistic flow behavior around the RAMSIS model, a prism layer mesh with 12 layers is included. The total mesh results in about 2 million cells. 


\section{Simulation and Linearization of the Calibration Conditions}

The flow diagram of the linearization procedure that the authors used can be seen in Figure 2.

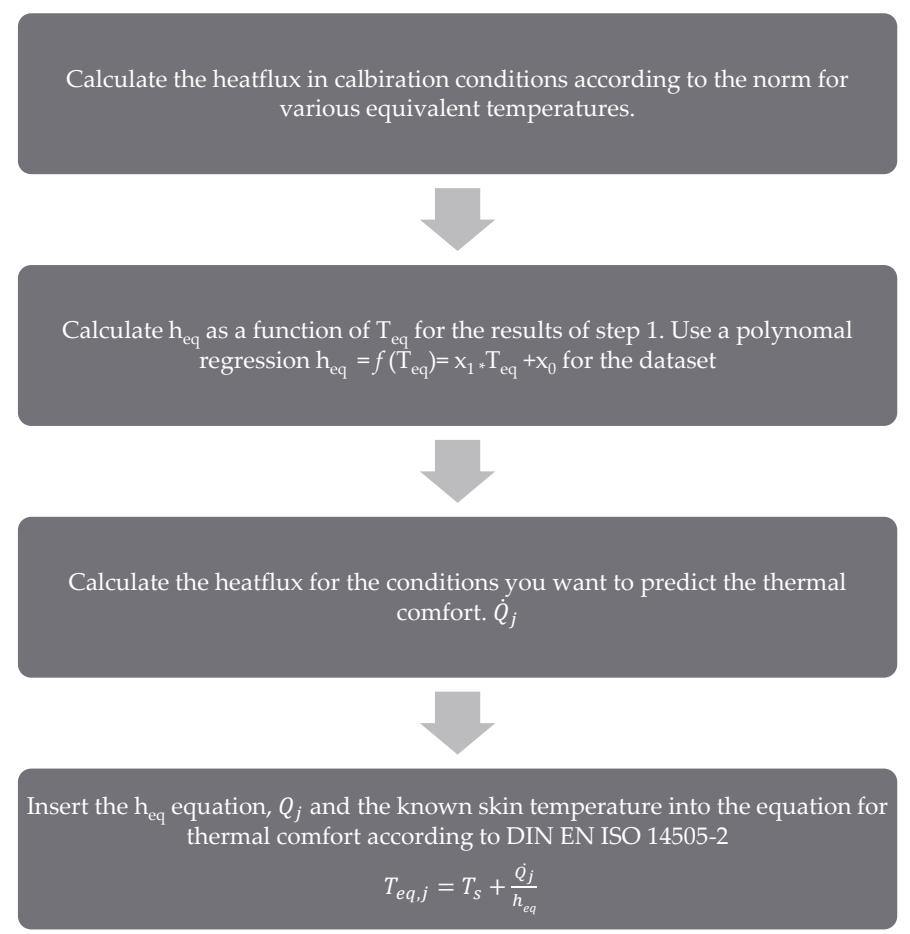

Figure 2. Flow chart for the linearization approach.

For the determination of the heat transfer coefficients, the following conditions are specified by the standard DIN EN ISO 14505-2 [5].

- Flow velocity $0.05 \mathrm{~m} / \mathrm{s}$;

- Temperature gradient $<0.4 \mathrm{~K} / \mathrm{m}$.

For a constant skin temperature of $34{ }^{\circ} \mathrm{C}$, different equivalent temperatures were specified to determine the dependence of the heat transfer coefficient. Because the heat flux depends on the temperature difference between the skin and the surroundings where the equivalent temperature is evaluated, it is possible to account for inhomogeneous temperature distributions when using a specific skin temperature in Equation (24). In this work, a homogenous temperature is used for simplification.

Figure 3 shows the heat flux on the RAMSIS geometry and the velocity fields, which result at an equivalent temperature of $25^{\circ} \mathrm{C}$. Three characteristic rays are formed as wake areas, in which the temperature of the flow in $+z$ direction has a longer length scale until mixing with the direct surroundings. The jets (white arrows in Figure 3) are significantly longer than the distance the flow travels along the body. The flow heats up faster per unit of travel as it passes the body and then releases the heat through mixing in the wake zone. The wake formation is induced by the head and the knee area. In addition, a small trailing zone is created in the vicinity of the feet. The trailing zones appear due to the slow flow speeds, as the air follows the body shape and then leaves at geometrically characteristic edges. The representation of the heat flows can be used to derive initial model-like impressions of the temperature sensation. For example, a test person in this configuration gives off more heat via the stomach than via the sides. 


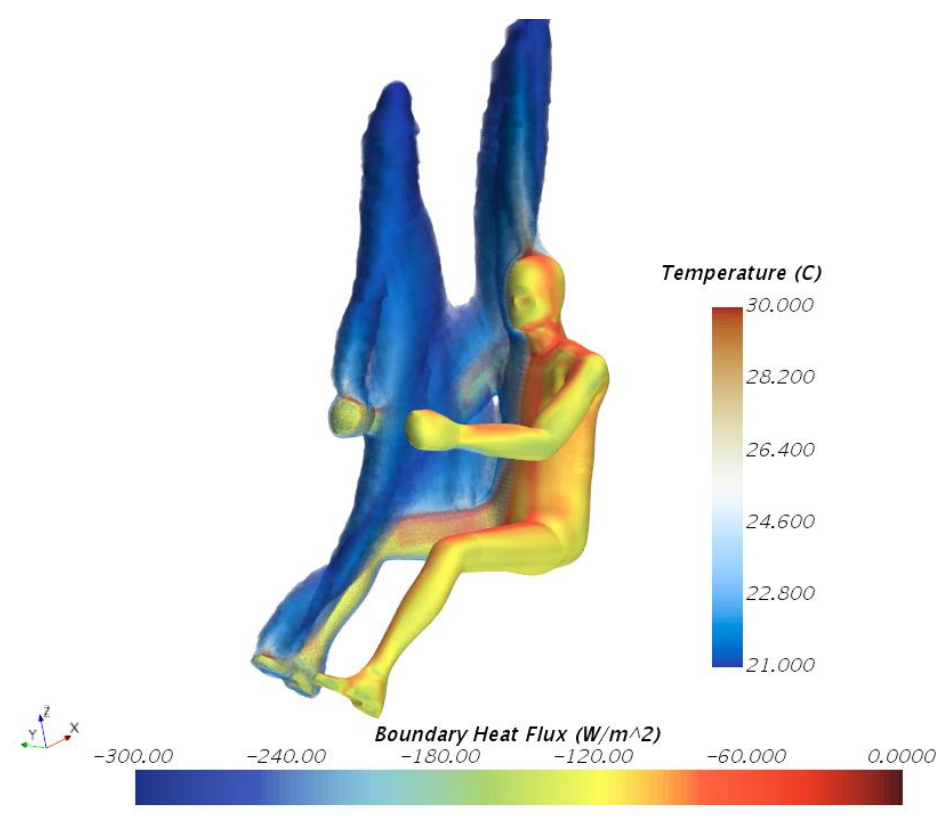

Figure 3. Boundary heat flux and temperature at $25^{\circ} \mathrm{C}$.

As a validation of the flow field, the qualitative results of PIV measurements by Mitterhofer et al. [38] were used. In their experiment, the same phenomena could be observed as in this study.

\subsection{Turbulence Models}

In fluid flow simulations, different methods are used to solve the non-linear NavierStokes equation system. A huge challenge is the correct calculation of turbulence effects using semi-empirical models and assumptions. In the industry, the RANS method (Reynolds-averaged Navier-Stokes) for turbulence modeling has become generally accepted, in which the time-dependent quantities velocity, pressure, and temperature are divided into an average and a fluctuation term and are then averaged over time in order to eliminate the fluctuation terms. A good overview of the topic can be found in the book of Ferziger and Perić [34].

Due to the averaging, Reynolds stress terms are introduced in the equation system, which has to be modeled to solve the system of equations. The equation system contains more unknown quantities than equations; hence, the Reynolds stress needs to be modeled. A common model is the Boussinesq approximation that treats the Reynolds stresses as viscous stresses [34], which defines the Reynolds stress tensor $\tau$ to

$$
\tau=2 \mu_{t} S-\frac{2}{3}\left(\mu_{t} \nabla \bar{u}\right) I
$$

Different methods for turbulence modeling have been established, where k-epsilon and k-omega models in different variations are most common. Kappa or $\mathrm{k}$ is the turbulent kinetic energy, epsilon is the turbulent dissipation rate, and omega is the specific dissipation rate.

\subsection{1. k-Epsilon Model}

$$
\begin{gathered}
\frac{\partial}{\partial t}(\rho k)+\nabla \cdot(\rho k \bar{v})=\nabla \cdot\left[\left(\mu+\frac{\mu_{1}}{\sigma_{k}}\right) \nabla \mathrm{k}\right]+P_{k}-\rho\left(\varepsilon-\varepsilon_{0}\right)+S_{k} \\
\frac{\delta}{\delta t}(\rho \varepsilon)+\nabla \cdot(\rho \varepsilon \bar{v})=\nabla\left[\left(\mu+\frac{\mu_{1}}{\sigma_{\varepsilon}}\right) \nabla \varepsilon\right]+\frac{1}{T_{e}} C_{\varepsilon 1} P_{\varepsilon}-C_{\varepsilon 2} f_{2} \rho\left(\frac{\varepsilon}{T_{e}}-\frac{\varepsilon_{0}}{T_{0}}\right)+S_{\varepsilon}
\end{gathered}
$$


The k-epsilon model is considered in both standard and Abe-Kondoh-Nagano formulation with a modified damping term near the wall. According to the literature, this model is particularly suitable for the simulation of heat transfer phenomena, as the model is derived for low Reynolds numbers [35,39].

\subsection{2. k-Omega Model}

$$
\begin{gathered}
\frac{\delta}{\delta t}(\rho k)+\nabla(\rho k \bar{v})=\nabla\left[\left(\mu+\sigma_{k} \mu_{t}\right) \nabla k\right]+P_{k}-\rho \beta^{*} f_{\beta^{*}}\left(\omega k-\omega_{0} k_{0}\right) S_{k} \\
\frac{\delta}{\delta t}(\rho \omega)+\nabla \cdot(\rho \omega \bar{v})=\nabla\left[\left(\left(\mu+\sigma_{\omega} \mu_{t}\right) \nabla \omega\right]+P_{\omega}-\rho \beta f_{\beta}\left(\omega^{2}-\omega_{0}^{2}\right)+S_{\omega}\right.
\end{gathered}
$$

The k-omega model was originally derived from Wilcox and then further developed by Menter [40]. In this work, the industry standard for turbulent flows, the k-omega model, in the form of the well-known Menter SST model, is used [41].

\subsubsection{Laminar Model}

In the laminar model, the turbulent friction terms in the Navier-Stokes equations are not calculated. Therefore, these flows are similar to potential flows.

\subsubsection{Turbulent Viscosity}

Depending on the model, the turbulent viscosity

$$
\mu_{t}=\rho \cdot C_{\mu} f_{\mu} \frac{k^{2}}{e}=\rho \cdot k \cdot \frac{\alpha_{*}}{\omega}
$$

is calculated with the transported quantities.

\subsubsection{Model Comparison}

The models are compared with approximate empirical equations from the work of Nilsson. In Nilsson's work, Nusselt correlations for simple bodies, such as cuboids and cylinders, are used to determine the heat transfer within a flow model [6].

If the heat transfer from the flow simulation is compared to the heat transfer from Nilsson [6], it is obvious that there are differences for the extremities such as arms and legs. The scatter within the turbulence models is smaller than the deviation to the empirical equations of Nilsson but still around 15\%; it is assumed that the difference to Nilsson can be explained because of the more simple geometry Nilsson used-see Figure 4 . This deviation could be attributed to the different positions of the arms and legs. In the Nilsson investigation, horizontal legs and arms are assumed, whereas in this work, the arms and legs are assumed to be in an ergonomic seating position. Therefore, an exact geometric mapping of the conditions is necessary to determine the heat transfer in calibration conditions. For all turbulence models, the qualitative course corresponds to that of the empirical equations. Therefore, it can be concluded that a realistic geometry surface mesh is more important than the turbulence model used. For the calculations in this work, the kw-SST all $y+$ model was used.

The heat transfer coefficients are averaged over the corresponding body part surface. Figure 5 shows the different heat transfers across the individual body parts for different equivalent temperatures. 


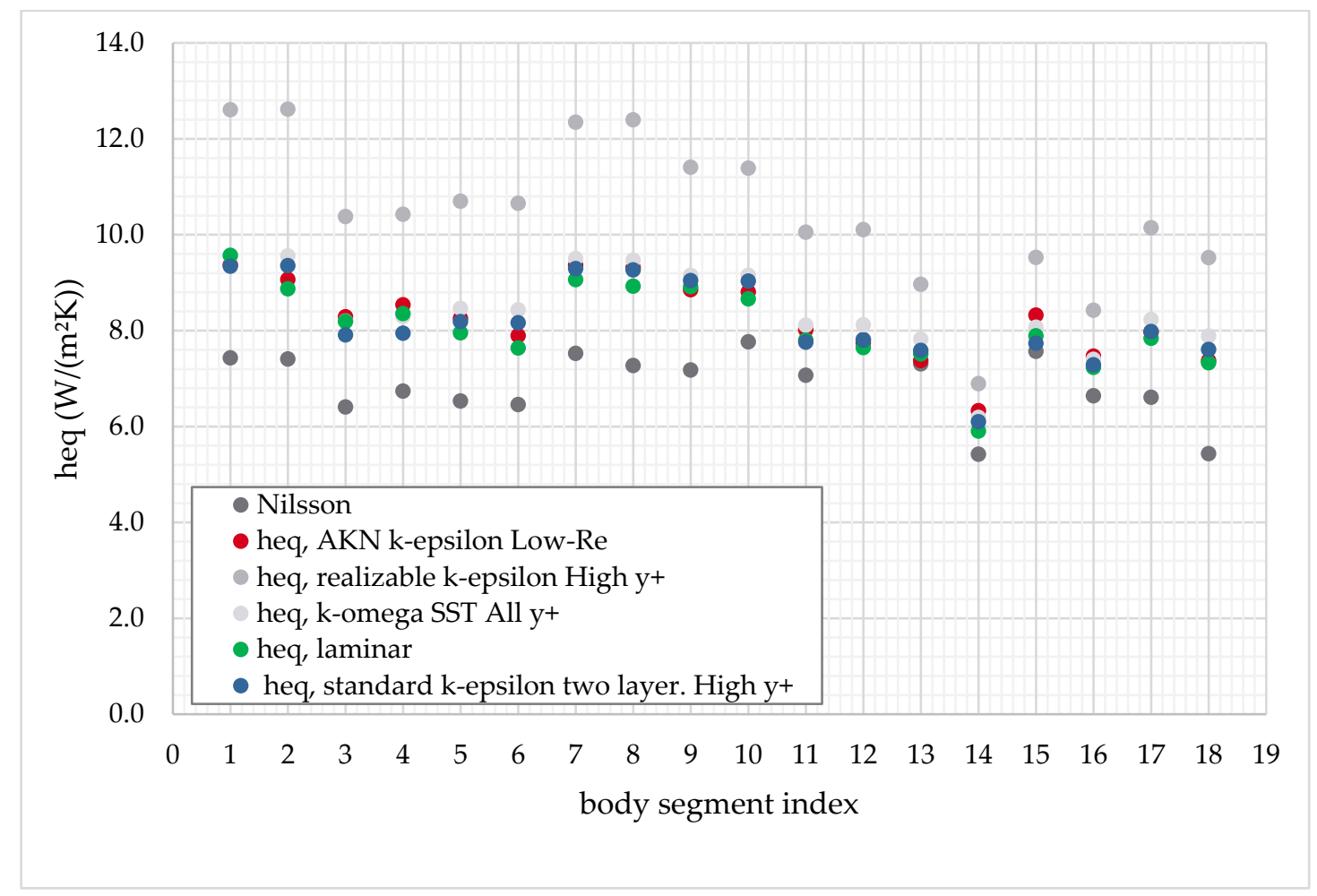

Figure 4. Comparison of the turbulence models regarding the heat transfer coefficients.

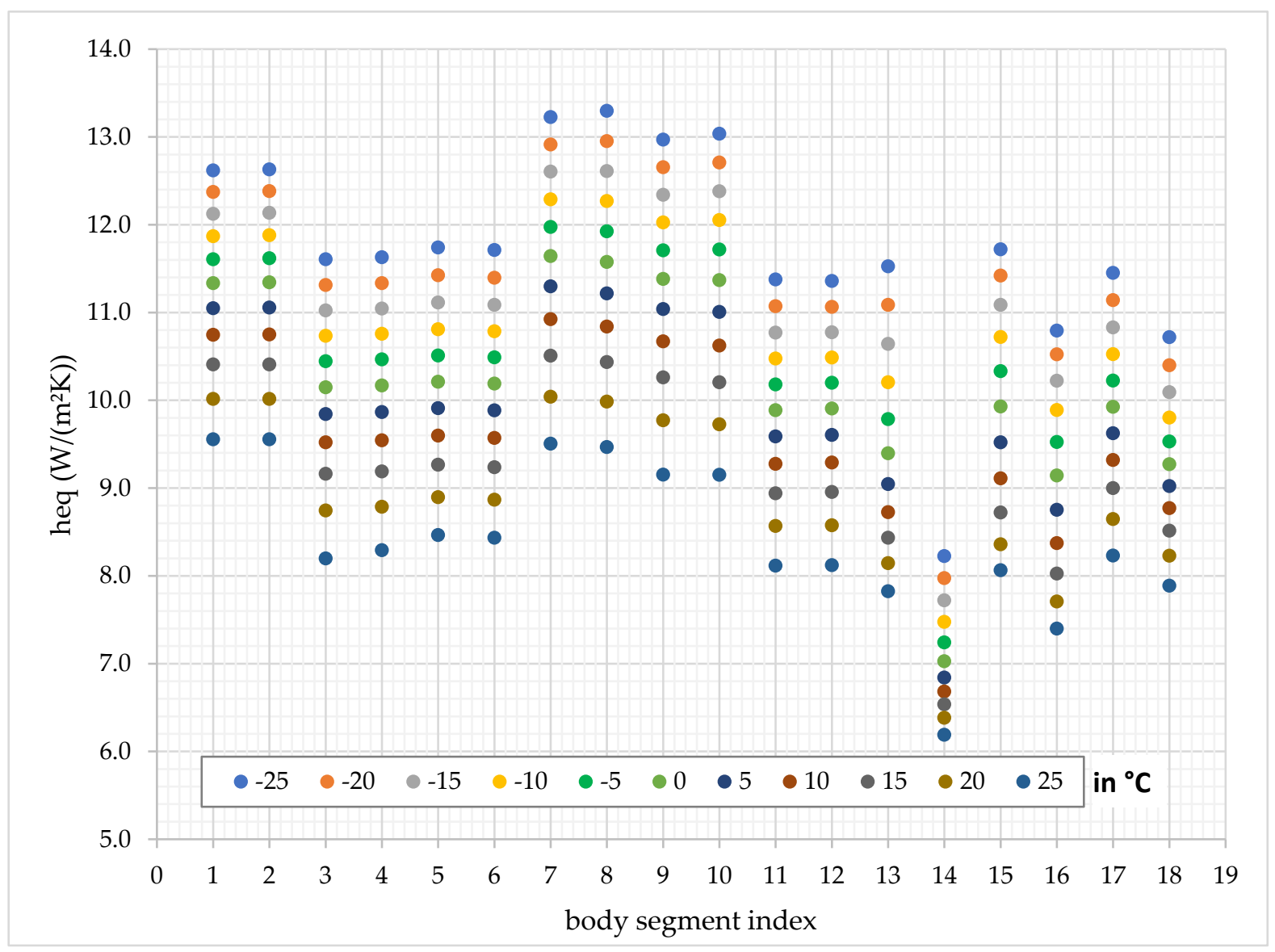

Figure 5. $h_{e q}$ for different equivalent temperatures. 
If the heat transfer coefficients are plotted against the absolute magnitude of the temperature difference between the equivalent and the skin temperature, it can be observed that the heat transfer in an equivalent temperature range from -25 to $25^{\circ} \mathrm{C}$ can be well approximated with the square of the temperature, as Figure 6 shows. For a better representation, different body parts are grouped together; the simulated values are shown as points and the approximation as a line in the same color. The coefficient of determination $\mathrm{R}^{2}$ is above 0.99 . The difference in the heat transfer coefficient in regard to the equivalent temperature is around $10 \%$, between 20 and $25^{\circ} \mathrm{C}$. For example, when a calculated comfortable equivalent temperature for a $34{ }^{\circ} \mathrm{C}$ body part is $25{ }^{\circ} \mathrm{C}$, not incorporating this behavior would lead to an error that is almost $50 \%$ of the width of the comfort area.

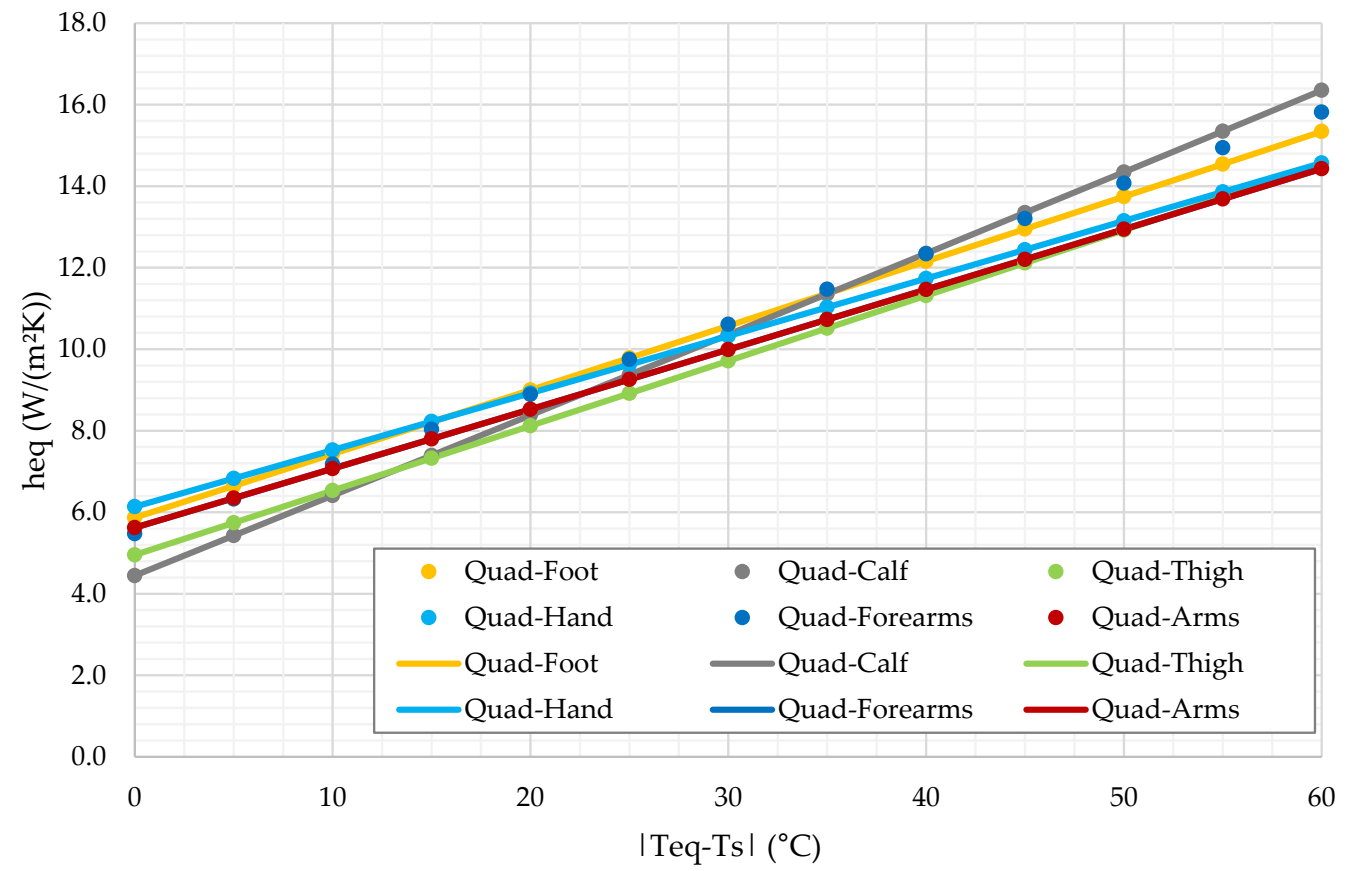

Figure 6. $h_{e q}$ quadratic relation for body segments group 1.

The parameters $a, b$, and $c$ are shown in Table 3 and Figure 7 as a result of the quadratic approximation.

Table 3. Body segments assignment by index, letter, and name.

\begin{tabular}{cccccc}
\hline Index $\mathbf{j}$ & Letter & Name & $\boldsymbol{a}_{j}$ & $\boldsymbol{b}_{j}$ & $\boldsymbol{c}_{j}$ \\
\hline 1 & $\mathrm{a}$ & Feet & $3.28823 \times 10^{-5}$ & 0.15589041 & 5.86819571 \\
\hline 2 & $\mathrm{~b}$ & Calf & $4.26080 \times 10^{-5}$ & 0.19588617 & 4.44609867 \\
\hline 3 & $\mathrm{c}$ & Thigh & $3.61242 \times 10^{-5}$ & 0.15755566 & 4.95349670 \\
\hline 4 & $\mathrm{~d}$ & Hand & $3.05666 \times 10^{-5}$ & 0.13870095 & 6.13626643 \\
\hline 5 & $\mathrm{e}$ & Lower arms & $3.79767 \times 10^{-5}$ & 0.14450724 & 5.62224012 \\
\hline 6 & $\mathrm{f}$ & Upper arms & $3.79767 \times 10^{-5}$ & 0.14450724 & 5.62224012 \\
\hline 7 & $\mathrm{~g}$ & Upper back & $3.61242 \times 10^{-5}$ & 0.15855566 & 5.71649670 \\
\hline 8 & $\mathrm{~h}$ & Chest & $2.68616 \times 10^{-5}$ & 0.15179780 & 3.90177959 \\
\hline 9 & $\mathrm{i}$ & Face & $3.05666 \times 10^{-5}$ & 0.13970095 & 6.16726643 \\
\hline 10 & $\mathrm{j}$ & Scalp & $3.05666 \times 10^{-5}$ & 0.20470095 & 4.58926643 \\
\hline 11 & $\mathrm{k}$ & Total & $3.51979 \times 10^{-5}$ & 0.15807988 & 5.02412499 \\
\hline 12 & 1 & Body & $3.61242 \times 10^{-5}$ & 0.12555566 & 4.17649670 \\
\hline
\end{tabular}




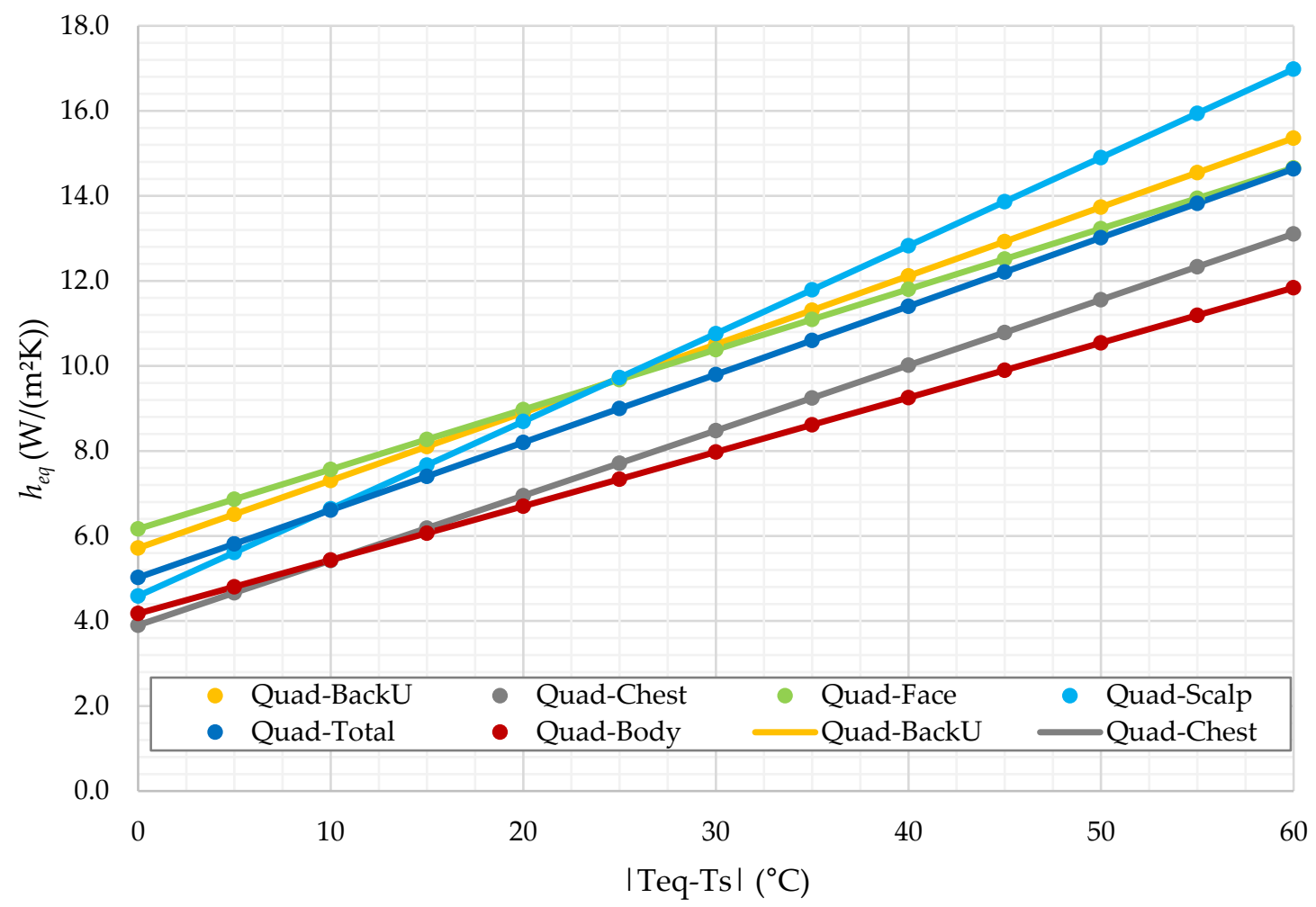

Figure 7. $h_{e q}$ quadratic relation for body segments group 2.

A coefficient matrix $K$ contains the parameters for the quadratic regression for each body segment via the index $j$ and is constructed as follows.

$$
K_{j}=\left(\begin{array}{ccc}
a_{j} & 0 & 0 \\
0 & b_{j} & 0 \\
0 & 0 & c_{j}
\end{array}\right)
$$

With the coefficient matrix $K$, the equivalent heat transfer coefficient can be calculated as

$$
h_{e q, j}=T_{e q, j}^{T} \cdot K_{j} \cdot T_{e q, j}
$$

If the approach is inserted into Equation (5), the following equation for the equivalent temperature of the different parts of the body is obtained:

$$
T_{e q, j}=T_{S}+\frac{\dot{Q}}{T_{e q, j}^{T} \cdot K_{j} \cdot T_{e q, j}}
$$

Since the goal of the present work is to reduce the effort for the $T_{e q}$ calculation, the approximation degree of $h_{e q}$ is reduced to a linear approach.

$$
h_{e q}=x_{j, 1} \cdot T_{e q, j}+x_{j, 0}
$$

The following coefficients $x_{j, 1}$ and $x_{j, 0}$ result from linear approximation with $\mathrm{R}^{2}>0.95$, see Table 4 . 
Table 4. Linear approximation coefficients for $h_{e q}$.

\begin{tabular}{cccc}
\hline Index $j$ & Name & $x_{j, 1}$ & $x_{j, 0}$ \\
\hline 1 & Feet & 0.15786335 & 5.85011047 \\
\hline 2 & Calf & 0.19844265 & 4.42266427 \\
\hline 3 & Thigh & 0.15972311 & 4.9336284 \\
\hline 4 & Hand & 0.14053494 & 6.1194548 \\
\hline 5 & Lower arms & 0.17237992 & 5.45193974 \\
\hline 6 & Upper arms & 0.14678584 & 5.60135294 \\
\hline 7 & Upper back & 0.16072311 & 5.6966284 \\
\hline 8 & Chest & 0.15340949 & 3.88700574 \\
\hline 9 & Face & 0.14153494 & 6.1504548 \\
\hline 10 & Scalp & 0.20653494 & 4.5724548 \\
\hline 12 & Total & 0.16019175 & 5.00476614 \\
\hline
\end{tabular}

In the diagrams (Figures 8 and 9), the linear approximation of the $h_{e q}$ is shown for the two body groups. The coefficient of determination is $\mathrm{R}^{2}>0.96$.

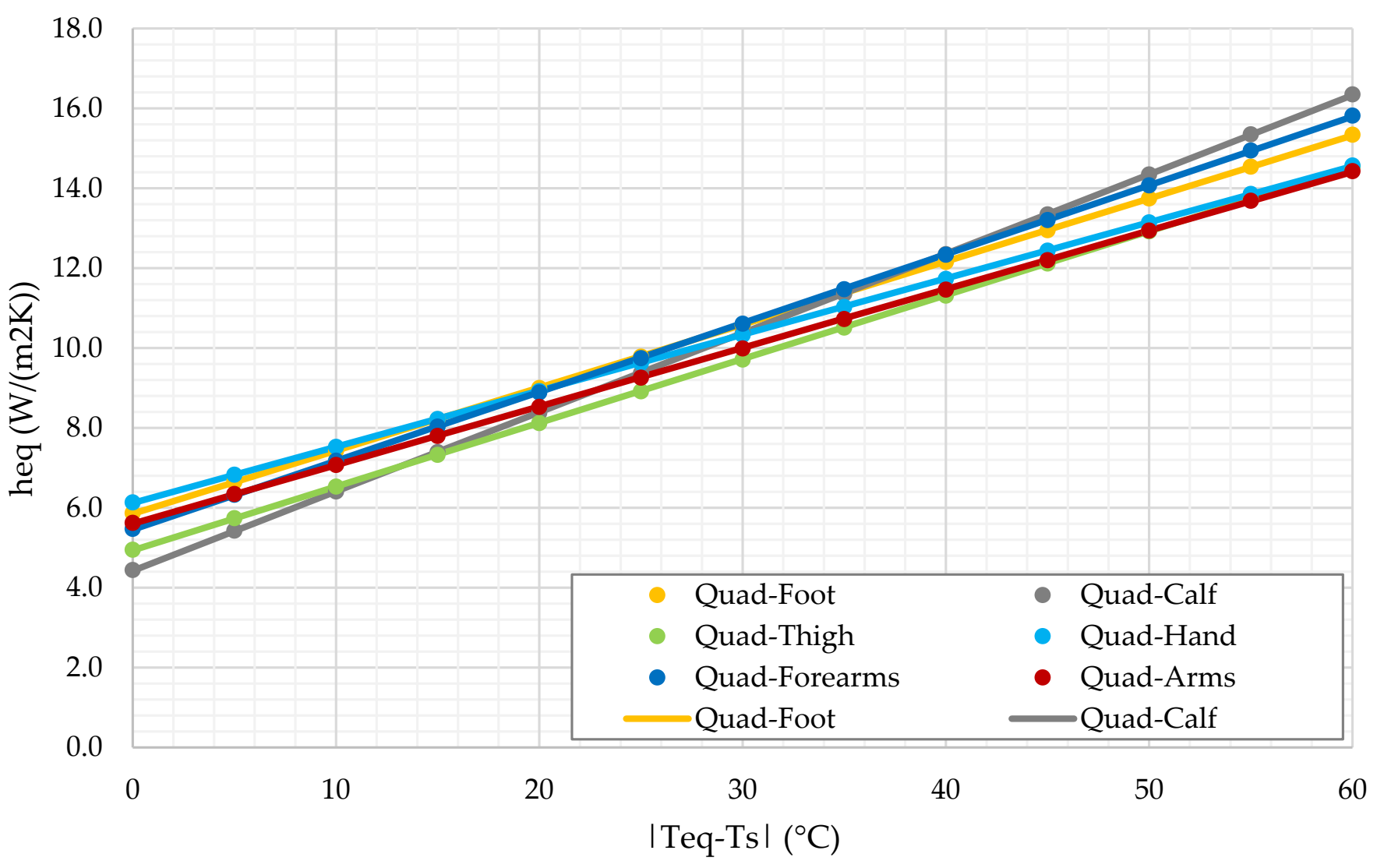

Figure 8. $h_{e q}$ linear relation for body segments group 1 . 


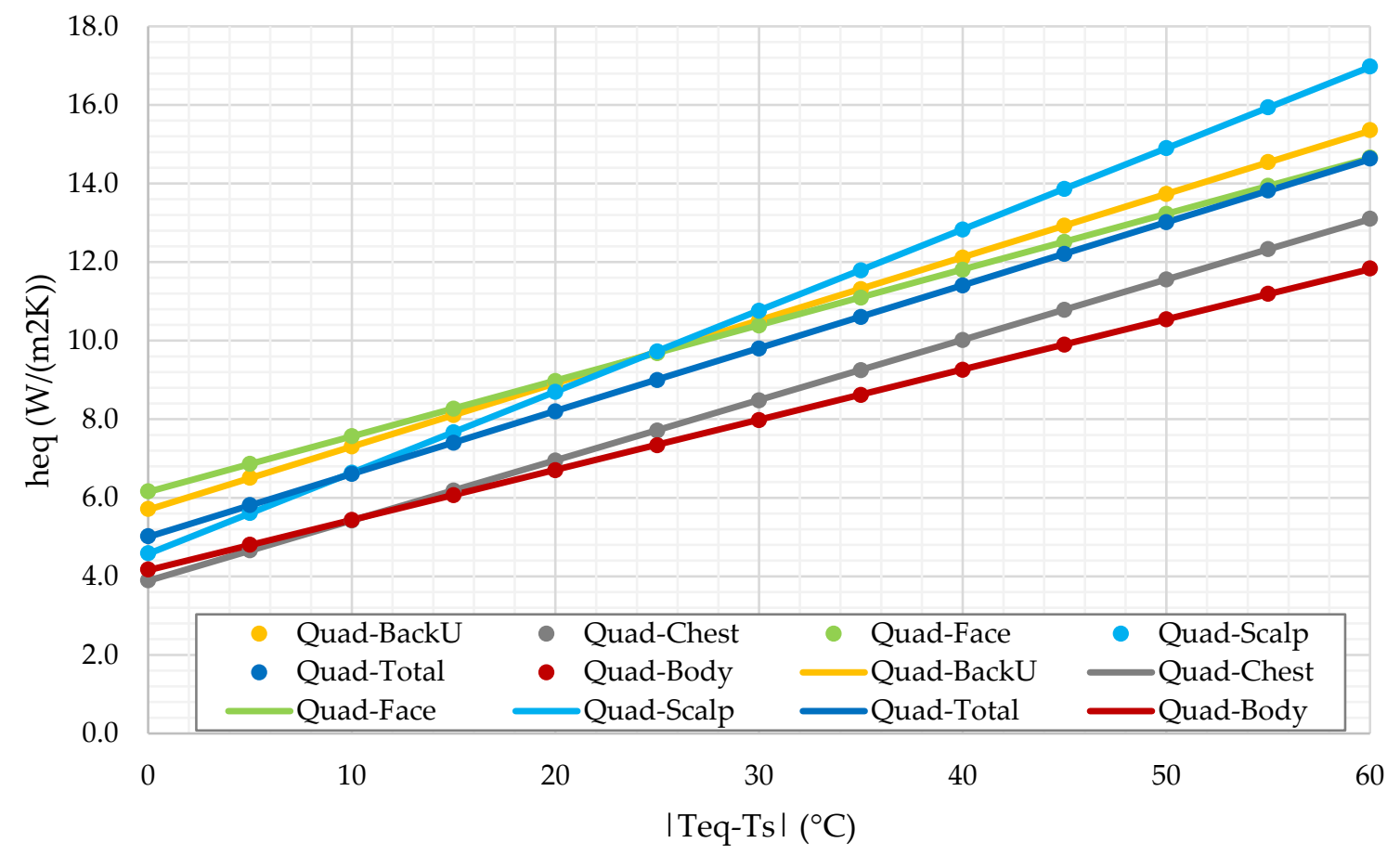

Figure 9. $h_{e q}$ linear relation for body segments group 2 .

The linear approximation is, however, less accurate than the quadratic approximation. Nevertheless, the errors introduced by the linear approximation are smaller than the variations due to measurement errors in the calibration chamber or the variance within the turbulence models. As well, variations in the assessment of thermal comfort votes by subject testing in a climatic chamber are large compared with the linear approximation error. Hence, the accuracy of the presented linear approximation is deemed sufficient for the presented context.

The formula for the equivalent temperature using linear approximation results in

$$
T_{e q, j}=T_{s}+\frac{Q_{j}}{x_{j, 1} \cdot T_{e q, j}+x_{j, 0}}
$$

After rearranging the equation according to the unknown temperature $T_{e q, j}$ and solving the resulting new equation, the equivalent temperature for the individual body parts can be written as

$$
T_{e q, j}=\frac{-x_{j, 0}-T_{s} \cdot x_{j, 1}}{2 \cdot x_{j, 1}} \pm \sqrt{\frac{\dot{Q}+T_{s} \cdot x_{j, 0}}{x_{j, 1}}+\left(\frac{x_{j, 0}-T_{s} \cdot x_{j, 1}}{2 \cdot x_{j, 1}}\right)^{2}} .
$$

The implementation in common flow simulations as user code is now possible as soon as only the physically reasonable values of the positive root are considered. Additionally, for implementation purposes, a limiter can be introduced to limit the denominator of the terms in the free flow range.

$$
T_{e q, j}=\sqrt{Q+\frac{T_{s} \cdot x_{j, 0}}{\min \left(x_{j, 1}, 10^{-5}\right)}+\left(\frac{x_{j, 0}-T_{s} \cdot x_{j, 1}}{2 \cdot \min \left(x_{j, 1}, 10^{-5}\right)}\right)^{2}}-\left(\frac{x_{j, 0}-T_{s} \cdot x_{j, 1}}{2 \cdot \min \left(x_{j, 1}, 10^{-5}\right)}\right)
$$

In order to implement the equivalent temperature approach, the two parameters are assigned to the corresponding body parts, and then a new scalar is created using Equation (26). The heat flow $Q$ of the respective face element can be used. 
The implementation in STARCCM+ as a field function can be expressed by the following formula:

Teq $=$

$-1 *$ sqrt $((\$\{$ BoundaryHeatFlux $\}+\$\{$ Ts $\} * \$\{$ heq_x 2$\} / \min (\$\{$ heq_x 1$\},-1 \mathrm{e}-5)+\operatorname{pow}((\$\{$ heq_x 2$\}-$ $\$\{$ Ts $\} * \$$ heq_x1 $\}$

$/\left(2^{*} \min (\$\{\right.$ heq_x $\left.\left.\left.\},-1 \mathrm{e}-5)\right), 2\right)\right)-\left(\$\{\right.$ heq_x 2$\}-\$\{\mathrm{Ts}\}^{*} \$\{$ heq_x $\left.\}\right) /\left(2^{*} \min (\$\{\right.$ heq_x 1$\left.\},-1 \mathrm{e}-5)\right)$

\section{Validation}

In the following section, the application and validation of the linearized approach from Section 3 are demonstrated for thermal comfort assessment of real case scenarios in two exemplary applications. It will be demonstrated that both simulation experiments can be improved with respect to local thermal comfort prediction without adding additional simulation complexity by applying the linearized equivalent temperature approach. Each scenario contains numerical manikins for thermal comfort evaluation. The results from these experiments are validated and are therefore used to validate the approach presented in this work as well.

\subsection{Generic Cubic Room}

\subsubsection{Model Setup}

Atish and Upender [42] published a study to predict thermal comfort with the Simplified Thermoregulatory Bio-heat (STB) equation for a cubic room with non-symmetric thermal boundaries. The authors varied the inlet temperature from a cubic room in $10 \mathrm{~K}$ steps between 10 and $50^{\circ} \mathrm{C}$ while keeping the right-hand side (RHS) of the room at $40{ }^{\circ} \mathrm{C}$ and the left-hand side (LHS) of the room at $10^{\circ} \mathrm{C}$, both sides from the perspective of the manikin. The body temperature is changing based on the computation of the STB equation according to the original work. The thermal comfort in the original study was evaluated using Fanger's model for the steady-state solutions.

The local thermal comfort for this test case is calculated using the linearized equivalent temperature calculation. Based on these results, the global thermal comfort has been calculated for validation purposes. Since no radiation was implemented in the original model and Fanger's model is used for a global thermal comfort calculation, the prediction of local thermal comfort is firstly introduced with the linearized equivalent temperature calculation in the following section. The computational mesh consists of polyhedral cells with a base size of $10 \mathrm{~mm}$ in the computational domain. A prism-based mesh was used on all elements near the surfaces except at the inlet and outlet. The manikin surfaces have a custom control, as shown in Figure 10, with a finer size of 5-50 mm. In advance of the final results, a grid study has been completed to confirm grid independence for the heat fluxes.

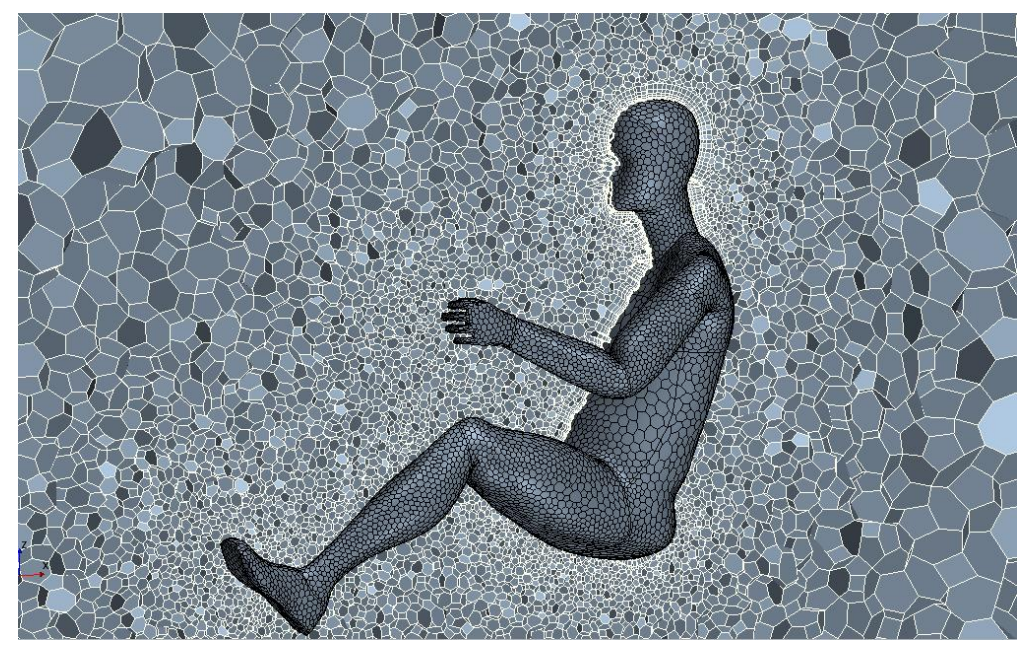

Figure 10. Manikin mesh refinement area. 
The kw-SST (Menter) turbulence model is used for the cubic room in combination with segregated fluid temperature and surface-to-surface radiation because it is commonly used in similar applications. The air is modeled as an ideal gas with a segregated fluid temperature, gravity, and surface-to-surface radiation. For the thermal comfort evaluation, the proposed method is used.

The boundary conditions are according to [42]:

- A constant velocity inlet with $0.5 \mathrm{~m} / \mathrm{s}$ in front of the manikin;

- An outlet behind the manikin;

- $\quad$ Left-hand side wall at $10{ }^{\circ} \mathrm{C}$, right-hand side wall at $40{ }^{\circ} \mathrm{C}$; the remaining walls are adiabatic.

\subsubsection{Global Results}

After calculating the equivalent temperature, the PMV for each body segment was calculated based on the formulas from Tomschke [43] and averaged over the body. Then, the PPD was calculated based on the formula according to ASHRAE [3].

$$
\mathrm{PPD}=100-95 \cdot e^{-\left(0.03353 \cdot \mathrm{PMV}^{4}+0.2179 \cdot \mathrm{PMV}^{2}\right)}
$$

Comparing the curve for the PPD in relation to the inlet temperature, both slopes look similar. The position of the minimum PPD is comparable with the linearized $T_{e q}$ approach when simulating with thermal radiation to the STB simulation without radiation. The biggest difference is at about $30{ }^{\circ} \mathrm{C}$, where the PPD with STB is $43 \%$, and the PPD for the linearized temperature approach is $27 \%$, as shown in Figure 11. The PPD for the linearized approach looks symmetrical around the minimum PPD, which is at $30{ }^{\circ} \mathrm{C}$ inlet temperature. The steeper increase in the PPD around that temperature in the STB model could be related to the missing radiation in the setup of the original test case or physiology aspects. The linearized equivalent temperature approach shows, for the global thermal sensation, almost the same results as the STB model with a coupled PMV and PPD calculation. The following chapter will show the error of the STB model in relation to local thermal comfort due to the missing radiation.

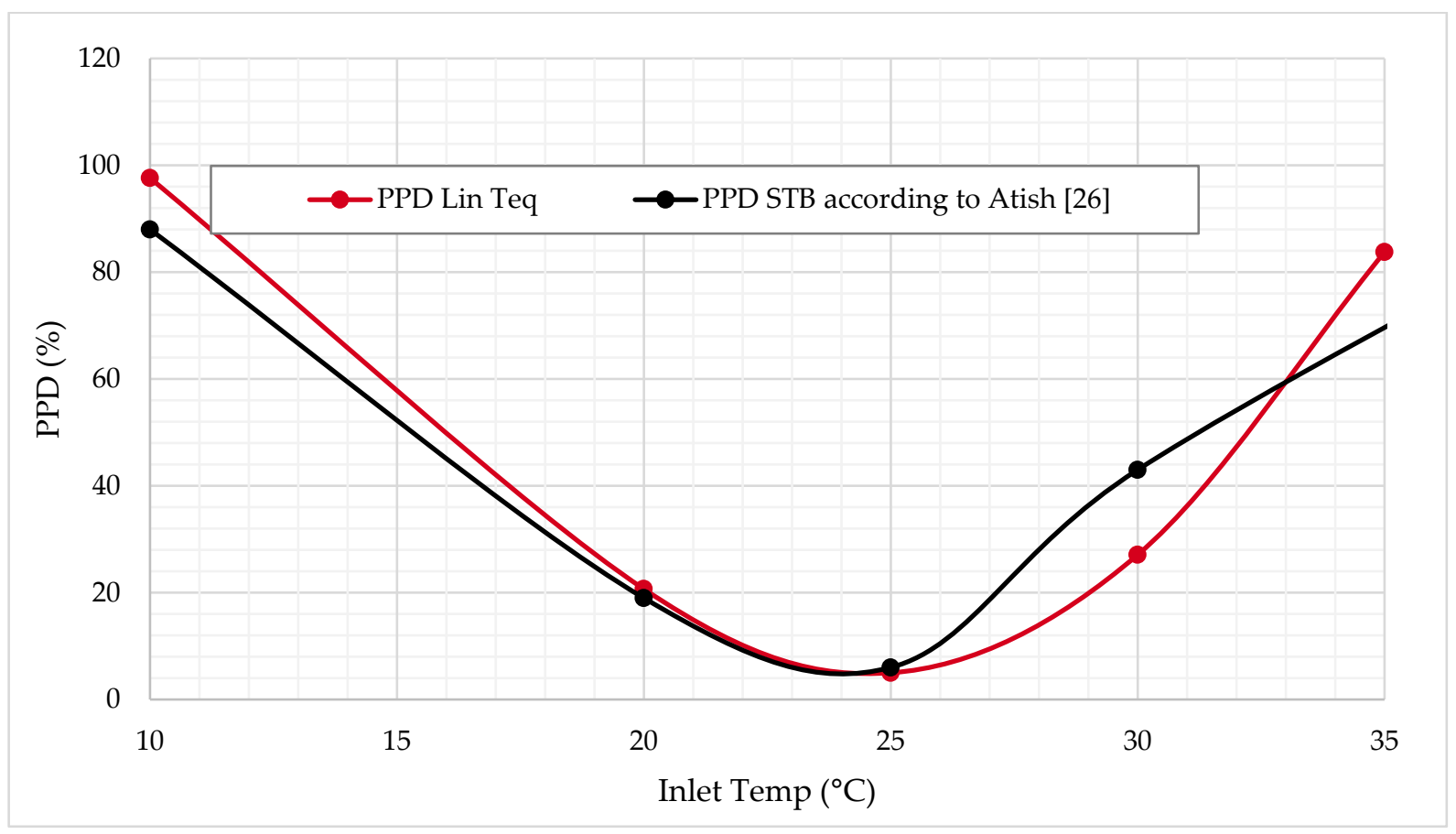

Figure 11. PPD in the cubic room. 


\subsubsection{Local Thermal Comfort}

Because of the neglected radiation, the original work by Atish and Upender [42] did not study the difference between the left-hand side and right-hand side of the body, even if the boundary conditions were asymmetrical. Figure 12 shows the calculated equivalent temperature for five different inlet temperatures for each body segment. For a better interpretation of the plot, dotted lines connect the body parts for every inlet temperature. According to Figure 11, the lowest PPD for the test persons is at an inlet temperature of $25^{\circ} \mathrm{C}$. In the local thermal comfort diagram, a difference between the left-hand side and the right-hand side for each extremity can be seen. The difference between larger extremities such as the LHS and RHS thigh and upper arm is higher than for smaller extremities such as the hands, feet, or calves. Keeping this observation in mind, a PMV of - 1 for the left side and a PMV of +1 for the right side would result in a PMV of 0 , which would suggest false results with respect to thermal sensation.

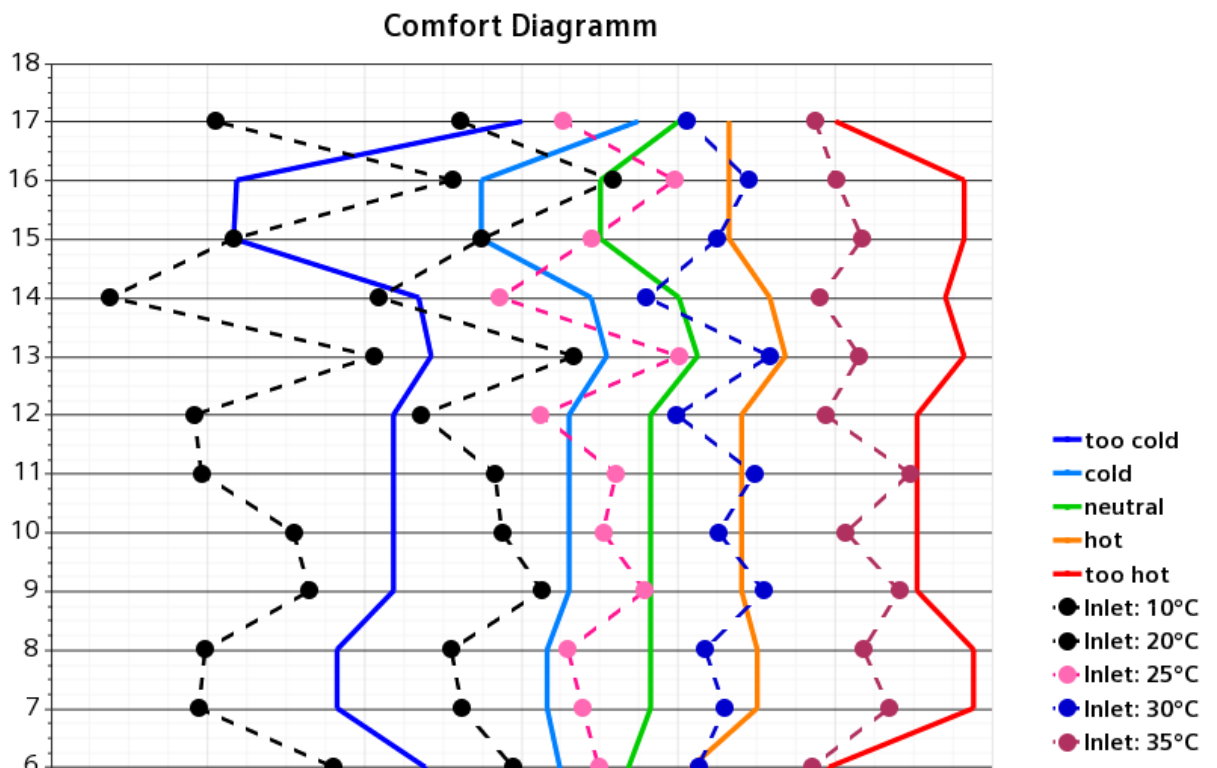

Figure 12. Equivalent temperature cubic room test case. Dotted lines for visual purposes.

Figure 12 shows the difference in the equivalent temperature for the LHS and RHS of the manikin at the comfort diagram. The equivalent temperature at the manikin surfaces that faces the colder LHS is between 5 and 10 degrees lower than at the side facing the hotter RHS. Even at a specific extremity, a difference can be seen in the surface plot in Figure 13, which would probably be neglected when simply averaging over an extremity. The difference is based on a dot product between the surface normal of a location on the manikin surface and the incoming radiation in the Y-direction. 


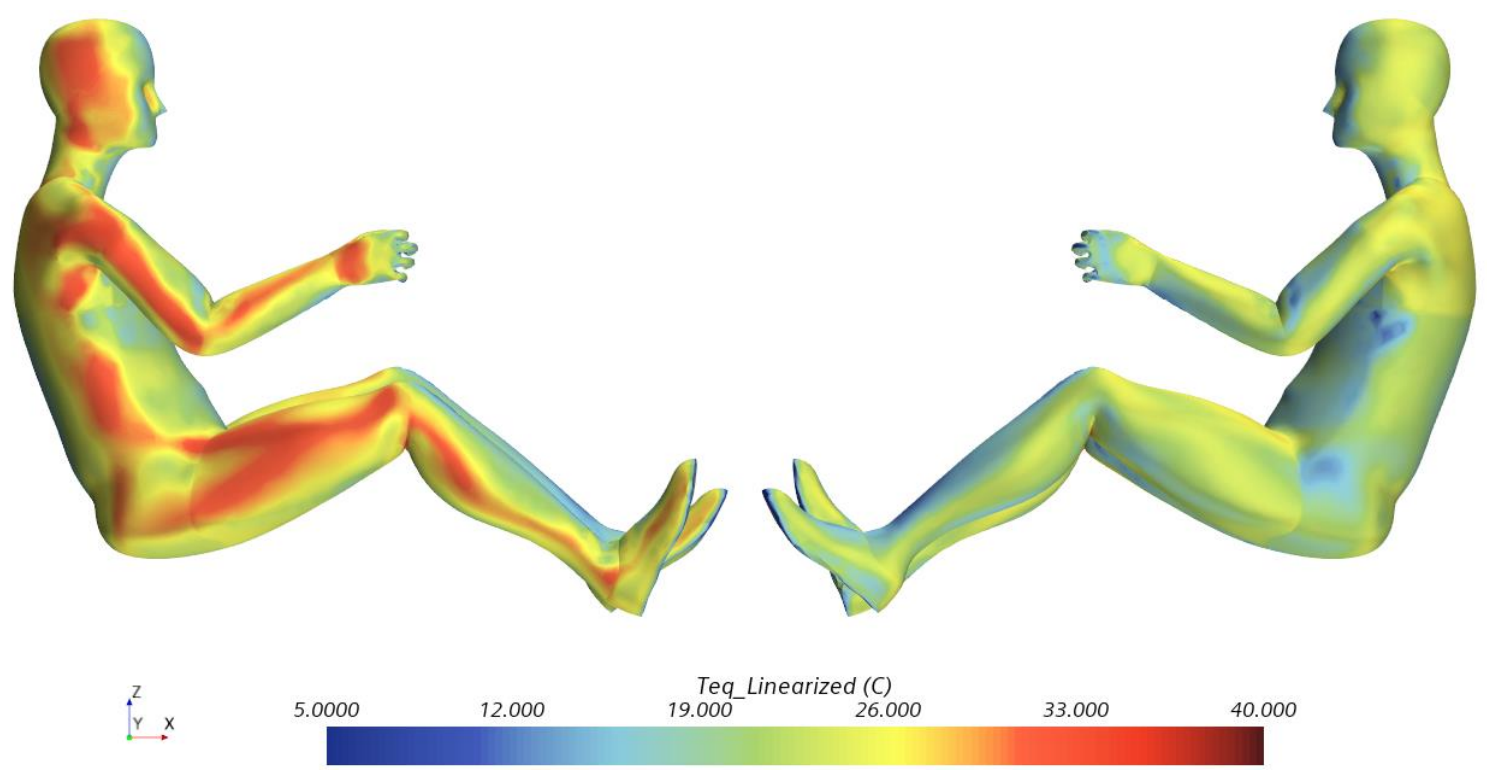

Figure 13. Linearized equivalent temperature at $25^{\circ} \mathrm{C}$ inlet temperature.

The heat flux for the manikin is defined as positive for receiving incoming radiation and negative for outgoing radiation. Figure 14 shows these radiation heat fluxes at the manikin's surface, which can radiate about $-55 \mathrm{~W} / \mathrm{m}^{2}$ to the colder LHS, while it receives $5 \mathrm{~W} / \mathrm{m}^{2}$ from the warmer side.

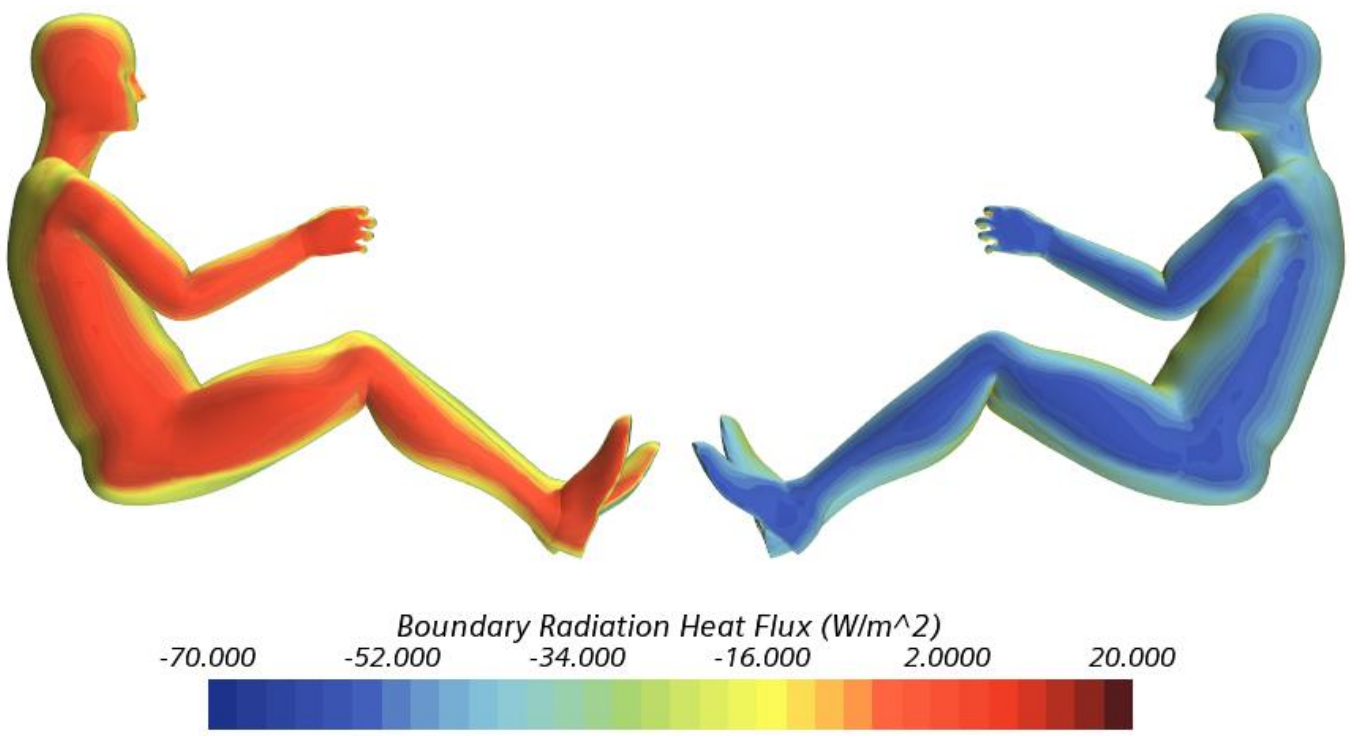

Figure 14. Radiation heat flux at the manikin at $25^{\circ} \mathrm{C}$ inlet temperature.

Comparing the radiation heat fluxes to the total heat flux at the boundary in Figure 15, the amount of heat the manikin received by radiation can be concluded to be a major driver for the thermal comfort in this specific case. The results for a global thermal sensation showed nearly no differences between the linearized, simplified approach and the detailed, complex model. Looking at the local thermal comfort, however, the results are diverging. With the linearized thermal comfort prediction approach for a manikin in the cubic room, a difference in thermal comfort could be examined between the LHS and RHS setup. The differences between the two sides of the body are related to the difference in radiative heat flux based on the asymmetrical thermal boundary conditions at the walls. 


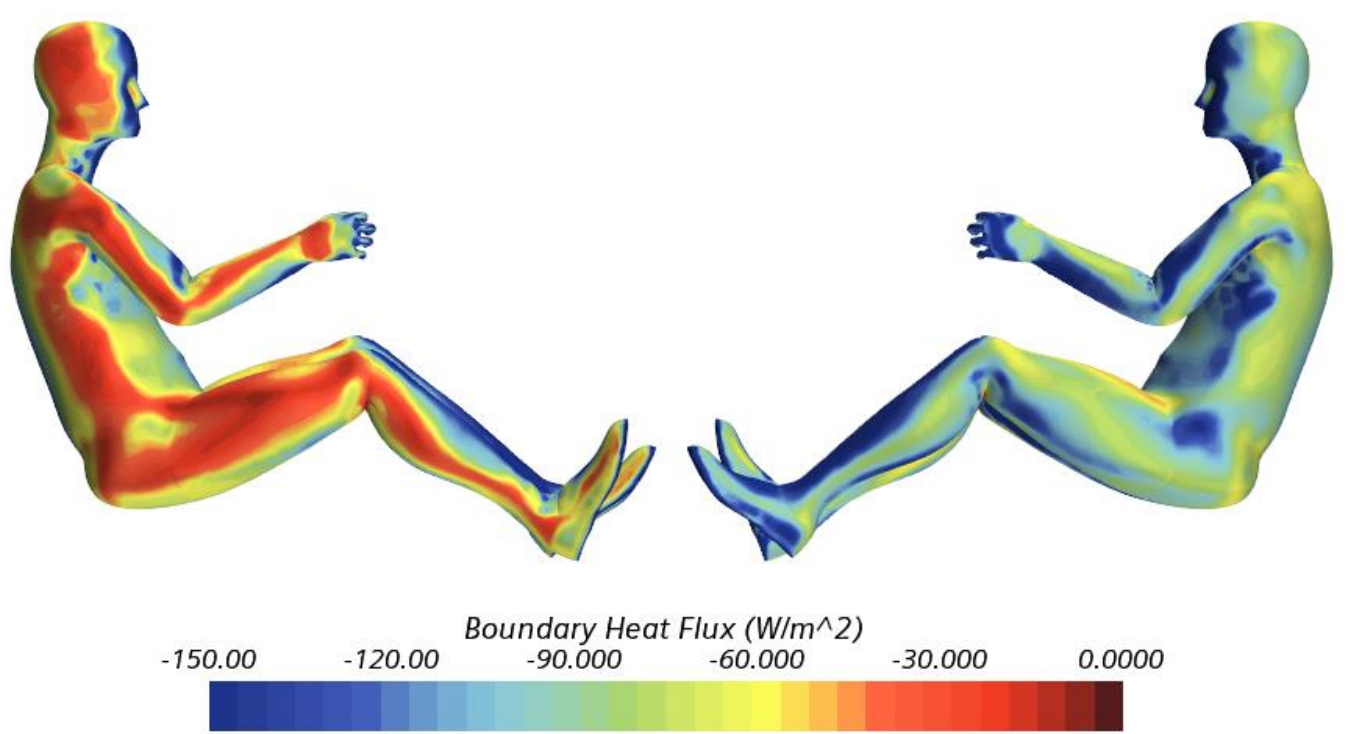

Figure 15. Total heat flux at the manikin at $25^{\circ} \mathrm{C}$ inlet temperature.

\subsection{Environmental Chamber Setup}

Cook et al. [44] describe a realistic scenario of a rectangular environmental chamber with a fan and a coupled simulation model to test and validate human comfort. The setup is adopted, and unknown settings are estimated as given in Table 5. The k-omega SST (Menter) turbulence model is used with surface-to-surface radiation, ideal gas for air, gravity, and a coupled solver to run a steady simulation. The fan is modeled as a simplified cylindrical body with an intake and outlet on the frontal surfaces connected by a fan interface with a generic fan curve. Transient effects such as the fan swirl are neglected.

Table 5. Boundary conditions and parameters for the environmental chamber.

\begin{tabular}{ll}
\hline Chamber size & $3.0 \times 5.4 \times 2.3 \mathrm{~m}(\mathrm{X}, \mathrm{Y}, \mathrm{Z})$ \\
\hline Fan & $\begin{array}{l}\text { Diameter: } 300 \mathrm{~mm} \\
\text { Width: } 100 \mathrm{~mm} \\
\left.\text { Type: Fan Interface (approximately } 200 \mathrm{~m}^{3} / \mathrm{h}\right)\end{array}$ \\
\hline Wall inlet & Type: Stagnation Inlet \\
\hline Ceiling opening & Type: Pressure Outlet \\
\hline Walls incl. ceiling & Adiabatic \\
\hline \multirow{2}{*}{ Manikin } & RAMSIS female, \\
& Lower fifth percentile \\
\hline Floor & $\mathrm{T}=34^{\circ} \mathrm{C}$ const. \\
\hline Ambient temperature & $\mathrm{T}=23{ }^{\circ} \mathrm{C}$ const. \\
\hline
\end{tabular}

The mesh consists of polyhedral cells with prism layer cells towards all surfaces except for the ceiling opening, the wall inlet, and the fan front and back faces. The number of prism layers is eight on the manikin and four for every other surface. The mesh base size is $50 \mathrm{~mm}$ with a target/minimum size of $15 / 10 \mathrm{~mm}$ on the manikin and fan surfaces. A cylindrical volumetric mesh refinement with $20 \mathrm{~mm}$ is used for the fan jet. These sizes result in a mesh containing around 700,000 volume cells, depicted in a plane section in Figure 16a. On the manikin surface, there are eight prism layers, as shown in Figure $16 \mathrm{~b}$. The final mesh settings are the results of a mesh study to find mesh independence. 


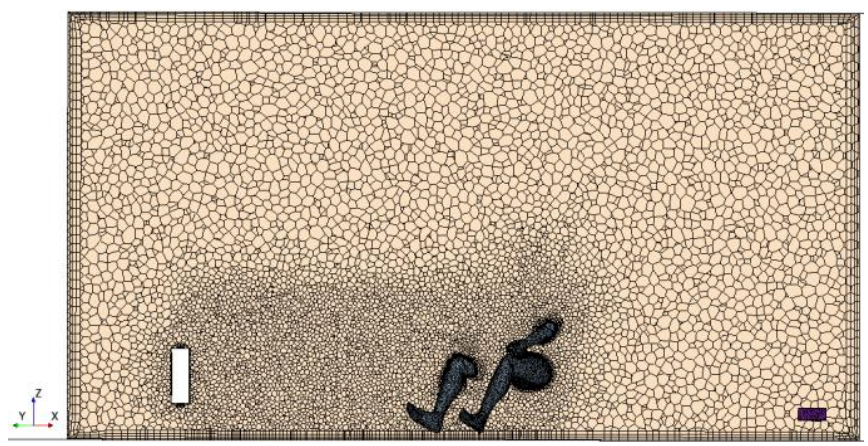

(a)

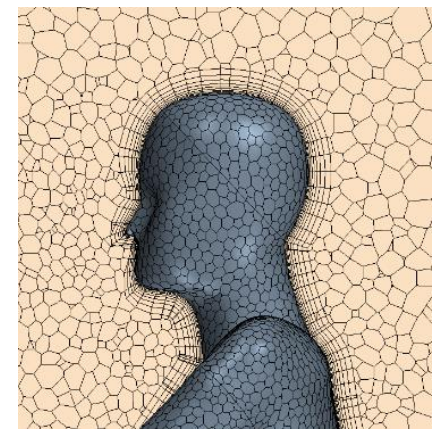

(b)

Figure 16. Mesh sections (a) through the manikin, fan, and chamber and (b) prism layers around the manikin.

\subsection{Global Results}

The vertical temperature distributions in the chamber in Figure 17 result from two steady simulations with the fan on or off. Without the fan, a distinct plume of hot air is rising up from the manikin, and the temperature stratification is stronger than with a running fan, similar to the results from Cook et al. [44].
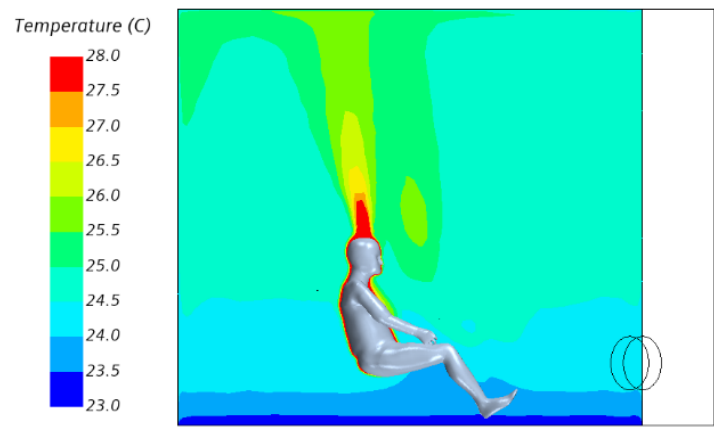

(a)

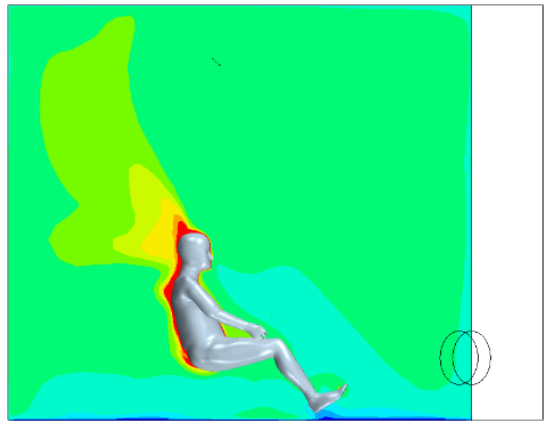

(b)

Figure 17. Vertical temperature distribution (a) without and (b) with a fan.

With an activated fan, the air temperature is slightly higher and more uniform throughout the chamber. The fan jet is oriented towards the manikin and partially increases the air velocity (Figure 18) around some of the manikin's body segments.

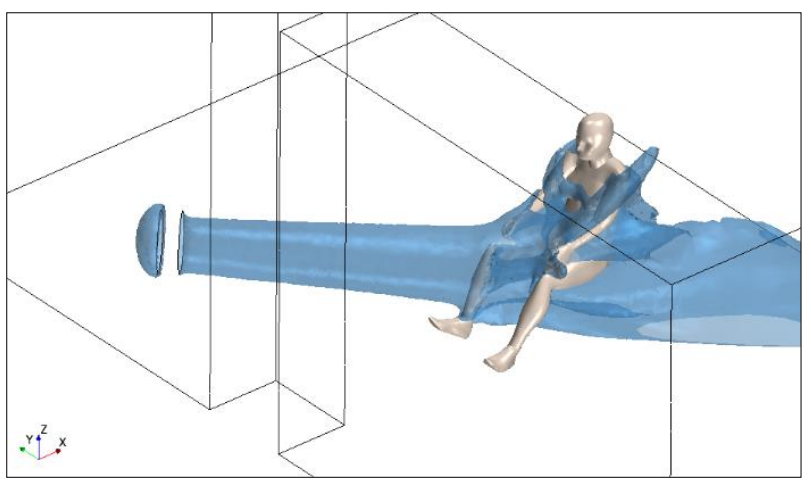

Figure 18. Velocity iso-surface of $0.4 \mathrm{~m} / \mathrm{s}$ to visualize the fan jet spreading over the manikin.

\section{Thermal Comfort}

The calculation of the equivalent temperature $T_{e q}$ yields an overall thermally neutral comfort level for the manikin with a deactivated fan around the neutral line (Figure 19). The hands tend to have higher $T_{e q}$ values because of their proximity to both legs (Figure 20). 
When the fan is activated, the predicted comfort level is lower. Especially, the right-hand side calf and left-hand side knee show low $T_{e q}$ values (Figure 19), which translate to a too-cold and cold comfort level for the right-hand side calf and left-hand side thigh, respectively. This is mainly due to the increased heat transfer caused by the higher velocity fan jet directly hitting these body segments. The arms, hands, and legs are cold but still comfortable, with the feet, right upper arm, upper back, and head being thermally neutral.

Torso

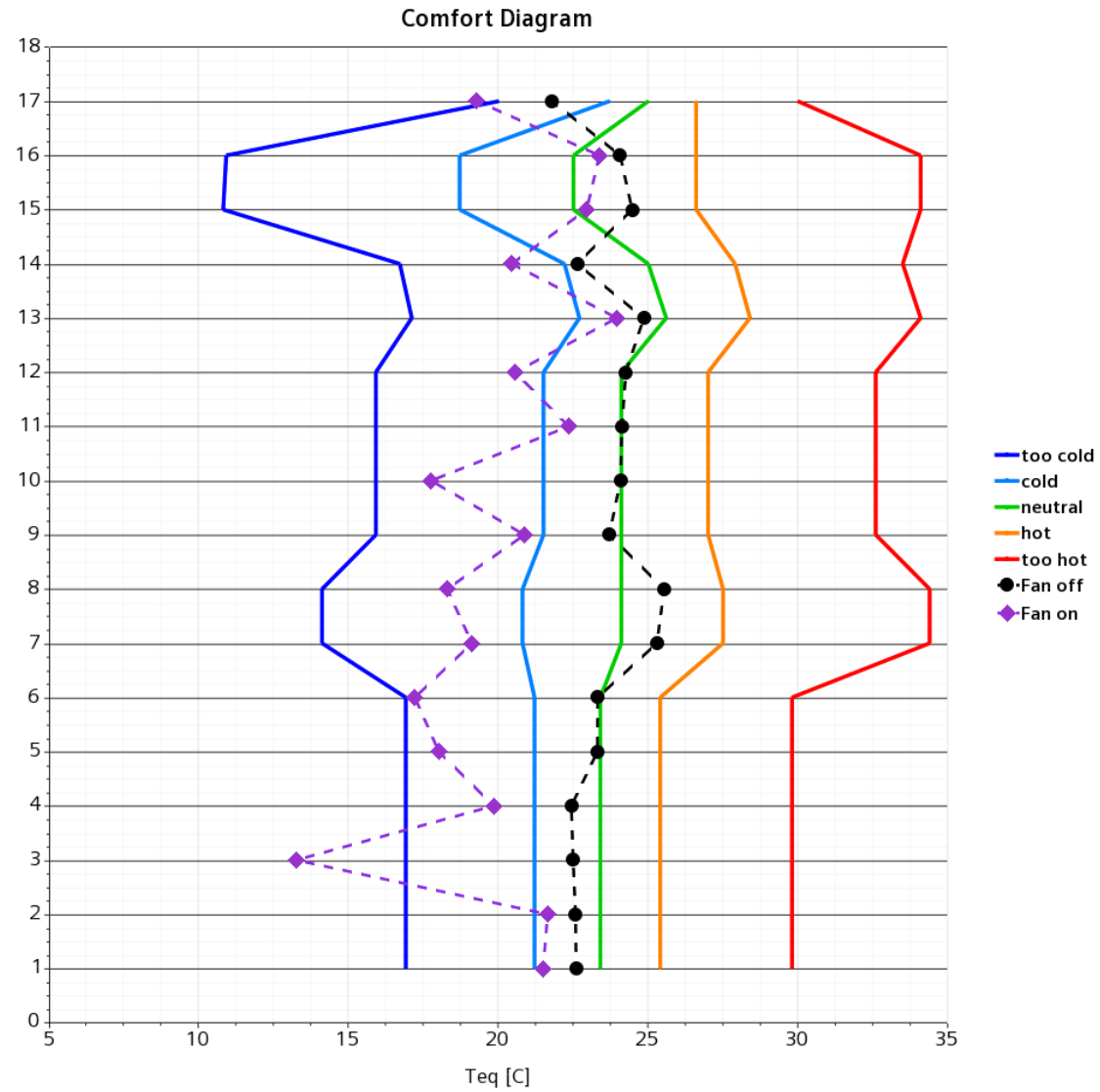

Figure 19. Comfort diagram with $T_{e q}$ values for the chamber with and without fan. Dashed lines for better visibility only.

\section{Fan off}

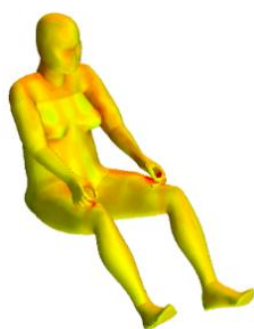

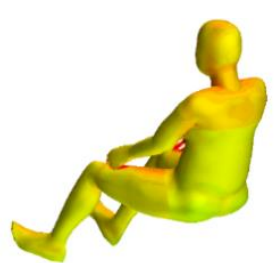

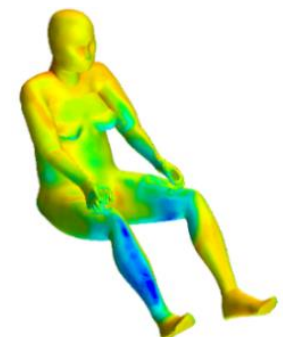

Fan on

Figure 20. Local $T_{e q}$ values on the manikin from two perspectives with left fan off and right fan on.

From these $T_{e q}$ values, a global PMV and PPD index can be calculated, such as the previous generic cubic room study. The PMV value yields a positive, neutral comfort level with a deactivated fan and a tendency to a negative slightly cold comfort level with an activated fan (Table 6). 
Table 6. Global PMV, PPD, and DTS values for the environmental chamber.

\begin{tabular}{ccccc}
\hline & $\begin{array}{c}\text { PMV with } \\
\boldsymbol{T}_{\boldsymbol{e q}}\end{array}$ & $\begin{array}{c}\text { PPD with } \boldsymbol{T}_{\boldsymbol{e q}} \\
\mathbf{( \% )}\end{array}$ & $\begin{array}{c}\text { DTS Final Value } \\
\text { (Equation (27)) }\end{array}$ & $\begin{array}{c}\text { PPD with DTS } \\
\text { (\%) }\end{array}$ \\
\hline Fan off & 0.38 & 8.1 & -0.19 & 5.7 \\
\hline Fan on & -0.55 & 11.2 & -0.47 & 9.6 \\
\hline
\end{tabular}

To compare the Dynamic Thermal Sensation (DTS) values from Cook et al. [44], their transient values were extrapolated with an exponential function (Equation (27)) to estimate a final value that can be compared to a steady-state simulation. This results in the final DTS values of -0.19 without a fan and -0.47 with a fan. Despite the transient formulation of the DTS index, it uses the same 7-point ASHRAE scale as the PMV index ranging from -3 to +3 and can therefore be compared with each other in terms of a thermal comfort prediction using the final value over a long period of time. This leads to a different comfort prediction when focusing on the global comfort level, where both settings (with/without fan) show a negative DTS value equivalent to a neutral to slightly cold comfort level, and the PMV values from $T_{e q}$ are positive or negative. However, the lower comfort level with the activated fan is clearly visible in this $T_{e q}$ and Cook et al.'s [44] approach.

$$
\begin{gathered}
\operatorname{DTS}(t)=a \cdot e^{-\frac{t}{b}}+\mathrm{c} \\
\text { with }\left\{\begin{array}{c}
a=0.520, b=344, c=-0.192 \text { without } \text { fan, } R^{2}=99.28 \% \\
a=0.794, b=350, c=-0.466 \text { with } \text { fan, } R^{2}=99.86 \%
\end{array}\right.
\end{gathered}
$$

\subsection{Computational Runtimes}

The total runtime of the steady-state simulations with 1000 iterations is around $50 \mathrm{~min}$ on an Intel ${ }^{\circledR}$ Xeon ${ }^{\circledR}$ Gold Linux workstation with 16 cores. Using the High Performance Computing Center Stuttgart (HLRS) HAWK cluster, the total runtime can be further reduced to, e.g., $7 \mathrm{~min}$ on 256 cores. Cook et al. [44] had a longer runtime, especially with the fan running about 1.5 days on 12 cores. This is a significant reduction for a fast comfort prediction with the $T_{e q}$ approach compared to the DTS method (Table 7), with respect to achieving similar results in terms of the PPD comfort index.

Table 7. Computational runtimes for the environmental chamber case study.

\begin{tabular}{cccc}
\hline Model & Fan & Runtime & PPD [\%] \\
\hline Linearized $T_{\text {eq }}$ Model & on & $<1 \mathrm{~h}$ & 8 \\
\cline { 2 - 4 } & off & $<1 \mathrm{~h}$ & 11 \\
\hline DTS & on & $34 \mathrm{~h}$ (average) & 6 \\
\cline { 2 - 4 } according to Cook et al. [44] & off & $18 \mathrm{~h}$ & 10 \\
\hline
\end{tabular}

\section{Summary}

In the DIN EN ISO 14505, the equivalent temperature method is proposed for the assessment of thermal comfort. Comfort diagrams, based on the work of Nilsson, indicate comfort in real conditions by means of the equivalent temperature [8]. This paper presented an approach to simplify the calculation of the equivalent temperature significantly by linearizing the heat transfer coefficient calculation based on the calculated heat transfer resistances in calibration conditions according to the standard DIN EN ISO 14505 for a temperature window of -25 to $+25^{\circ} \mathrm{C}$. Subsequently, a quadratic and linear approach is chosen for the approximation of the heat transfer coefficients. The linear approach shows a deviation of less than $5 \%$ in the heat transfer coefficients, which is small compared to the influences of different turbulence models or inaccuracies in the comfort assessment in general. Two test cases show the application of the implemented linearization for a generic cubic room and an environmental chamber, respectively. The first test case is extended 
by a local thermal comfort prediction with the linearized $T_{e q}$ approach. The second test case is used to show the significant reduction in computation time for a faster thermal comfort prediction.

\section{Conclusions}

The linearization approach helps to reduce the effort to predict the thermal comfort considerably for the user, which will allow a broader application in the future. This work shows the procedure to linearize the thermal comfort prediction as well as the implementation in a state-of-the-art CFD software. The simulation of thermal comfort will, in the future, tend to have more complex models with the influence of moisture and thermophysiology. All of these effects will be easy to implement in the presented approach using the linearization according to the presented method. Comparing the results with the results of an STB thermophysiology model shows that the contribution in the calibration conditions is comparably small. Effects such as sweating, shivering, and higher dimensional effects that do not depend on the equivalent temperature directly can be neglected in the linearization approach as long as they represent only a minor contribution to the calibration conditions. To implement these effects of the human body for the working conditions, they can just be incorporated in the application simulations while keeping the linearization approach for the equivalent conditions with the linearization coefficients presented in this work. Nevertheless, it should be noted that there may be environmental conditions, such as high humidity, where the effects play a major role. Comparing the results for the environmental chamber with respect to the calculation time, the linearized approach shows its advantages above coupled approaches like the DTS method. In summary, the presented linearization is the first step to make thermal comfort predictions more attainable for a larger audience. Because no partial differential equation has to be solved, the linearization method improves the application of the equivalent temperature method further because of its easy implementation. Thanks to the increased performance, the linearized $T_{e q}$ approach enables more complex thermal comfort simulations in the future, such as the interaction of many occupants in a room, for example. The performance increase is not a disadvantage in relation to the accuracy. It can be shown that the influence of the turbulence model on the heat transfer is higher than the influence of the linearization. Rather, the linearization includes the dependence of the heat transfer on the equivalent temperature, which has often been neglected so far. This approach enables future work to consider the simulative thermal comfort evaluation with an easy-to-implement calculation approach. Since this work is only focused on the simulation practice of a thermal comfort prediction, there should be additional experimental validation to demonstrate the real-world accuracy. As the described approach is in accordance with the DIN EN ISO 14505, any possible difference can only arise from the minor loss in accuracy due to the linearization of the heat transfer coefficients $h_{\mathrm{eq}}$ or the standard itself. Possible real-world differences could arise from environmental specific effects on the aerodynamics, time-dependent and varying skin temperatures, and the consideration of human-related differences in clothing, stature, and body shape, which are not fully considered in the standard.

Author Contributions: Conceptualization, C.R., L.F., J.F., C.V.T.; methodology, C.R. and L.F. software, C.R. and L.F.; formal analysis, J.F., C.V.T., C.R.; writing-original draft preparation, C.R.; writing-review and editing, C.R., L.F., J.F., C.V.T. All authors have read and agreed to the published version of the manuscript.

Funding: This research received no external funding.

Conflicts of Interest: The authors declare no conflict of interest. 


\section{References}

1. Voelker, C.; Alsaad, H. Simulating the human body's microclimate using automatic coupling of CFD and an advanced thermoregulation model. Indoor Air 2018, 28, 415-425. [CrossRef] [PubMed]

2. Streblow, R. Thermal Sensation and Comfort Model for Inhomogeneous Indoor Environments. Dissertation's Thesis, ON Energy Research Center, Tsukuba, Japan, 2010.

3. ASHRAE-55. Refrigerating and Air-Conditioning Engineers: Thermal Environmental Conditions for Human Occupancy. Atlanta. 2004. Available online: https:/ /www.ashrae.org/technical-resources/bookstore/standard-55-thermal-environmentalconditions-for-human-occupancy (accessed on 13 September 2021).

4. Fanger, P.O.; Krieger, R.E. Thermal Comfort, Malabar; Bruel \& Kjaer: Nærum, Denmark, 1982.

5. DIN EN ISO 14505-2. Ergonomics of the Thermal Environment-Evaluation of Thermal Environment; Beuth: Berlin, Germany, 2004.

6. Nilsson, H.; Holmér, I.; Bohm, M.; Norén, O. Equivalent Temperature and Thermal Sensation—Comparison with Subjective Responses; ATA: Bologna, Italy, 1997.

7. Nilsson, H.O. Comfort Climate Evaluation with Thermal Manikin Methods and Computer Simulation Models, 3rd ed.; National Institute for Working Life: Stockholm, Sweden, 2004; p. 37.

8. Fiala, D. Dynamic Simulation of Human Heat Transfer and Thermal Comfort, Leicester. Ph.D. Thesis, De Montfort University, Leicester, UK, 1998.

9. Fiala, D.; Havenith, G.; Kampmann, B.; Jendritzky, G. UTCI-Fiala multinode model of human heat transfer and temperature regulation. Int. J. Biometerool. 2019, 56, 429-441. [CrossRef] [PubMed]

10. Kingma, B. Human Thermoregulation: A Synergy between Physiology and Mathematical Modeling. Ph.D. Thesis, University of Maastricht, Maastricht, The Netherlands, 2021.

11. Fiala, D.; Psikuta, A.; Jendritzky, G.; Paulke, S. Physiological modeling for technical, clinical and research applications. Front. Biosci. 2010, 2, 939-968. [CrossRef] [PubMed]

12. Schwarz, M.; Krueger, M.W.; Busch, H.-J.; Benk, C.; Heilmann, C. Model-based assessment of tissue perfusion and tempera-ture in deep hypothermic patients. IEEE Trans. Biomed. Eng. 2010, 57, 1577-1586. [CrossRef] [PubMed]

13. Xiaoyang, S.; Eckels, S.; Zhongquan, T. An improved thermal model of the human body. HvacEr Res. 2011, 18, 323-338.

14. Tang, Y.; He, Y.; Shao, H.; Ji, C. Assessment of comfortable clothing thermal resistance using a multi-scale human thermoregulatory model. Int. J. Heat Mass Trans. 2016, 98, 568-583. [CrossRef]

15. Dayi, L.; Qingjan, C. A two-dimensional model for calculating heat transfer in the human body in a transient and non-uniform thermal environment. Energy Build. 2016, 118, 114-122.

16. Foda, E.; Sirén, K. A new approach using the Pierce two-node model for different body parts. Int. J. Biometeorol. 2010, 55, 519-532. [CrossRef]

17. Kotb, H.; Khalil, E.E. Passengers' Thermal Comfort in Wide-Body Aircraft Cabin. In AIAA Propulsion and Energy 2020 Forum; American Institute of Aeronautics and Astronautics: Reston, VA, USA, 2020.

18. Sondes, I.; Zied, D. Numerical simulation and experimental validation of the ventilation system performance in a heated room. Air Qual. Atmos. Health 2020, 14, 171-179.

19. Khatoon, S.; Kim, M.-H. Thermal Comfort in the Passenger Compartment Using a 3-D Numerical Analysis and Comparison with Fanger's Comfort Models. Energies 2020, 13, 690. [CrossRef]

20. Lange, P.; Schmeling, D.; Hörmann, H.J.; Volkmann, A. Comparison of local equivalent temperatures and subjective thermal comfort ratings with regard to passenger comfort in a train compartment. Mater. Sci. Eng. 2019, 609, 032042. [CrossRef]

21. Schmidt, C.; Wölki, D.; Metzmacher, H.; van Treeck, C.A. Equivalent contact temperature (ECT) for personal comfort as-sessment as extension for ISO 14505-2, WINDSOR Rethinking Comfort Proceedings. Windsor 2018, 451-466.

22. Sales, R.B.C.; Pereira, R.R.; Aguilar, M.T.P.; Cardoso, A.V. Thermal comfort of seats as visualized by infrared thermography. Appl. Ergon. 2017, 62, 142-149. [CrossRef]

23. Cengiz, T.G.; Babalık, F.C. The effects of ramie blended car seat covers on thermal comfort during road trials. Int. J. Industr. Ergon. 2009, 39, 287-294. [CrossRef]

24. Schmidt, C.; Praster, M.; Wölki, D.; Wolf, S.; van Treeck, C. Rechnerische und probandengestützte Untersuchung des Einflusses der Kontaktwärmeübertragung in Fahrzeugsitzen auf die thermische Behaglichkeit. FAT 2013, 261, 1-76.

25. Taghinia, J.H.; Rahman, M.; Lu, X. Effects of different CFD modeling approaches and simplification of shape on prediction of flow field around manikin. Energy Build. 2018, 170, 47-60. [CrossRef]

26. Yousaf, R.; Cook, M.; Wood, D.S.; Yang, T. CFD and PIV based investigation of indoor air flows dominated by buoyancy effects generated by human occupancy and equipment. In Proceedings of the 12th Conference of International Building Performance Simulation Association, Sydney, Australia, 14-16 November 2011.

27. Lee, C.; Honma, H.; Melikov, A. An experimental study on convective heat transfer coefficient distribution on thermal manikin by air flow with various velocities and turbulence intensities. Trans. Arch. Inst. Japan 2003, 429, 25-31.

28. Gao, S.; Ooka, R.; Oh, W. Formulation of human body heat transfer coefficient under various ambient temperature, air speed and direction based on experiments and CFD. Build. Environ. 2019, 160, 106168. [CrossRef]

29. Yoshiichi Ozeki, H.; Oi, Y.; Ichikawa, A. Matsumoto, Evaluation of Equivalent Temperature in a Vehicle Cabin with a Numerical Thermal Manikin (Part 2): Evaluation of Thermal Environment and Equivalent Temperature in a Vehicle Cabin; SAE Technical Paper; SAE: Warrendale, PA, USA, 2019. 
30. Oi, H.; Ozeki, Y.; Suzuki, S.; Ichikawa, Y.; Matsumoto, A.; Takeo, F. Evaluation of Equivalent Temperature in a Vehicle Cabin with a Numerical Thermal Manikin (Part 1): Measurement of Equivalent Temperature in a Vehicle Cabin and Development of a Numerical Thermal Manikin; SAE: Warrendale, PA, USA, 2019.

31. Morishita, M.; Uchida, T.; Mathur, G.D.; Kato, T.; Matsunaga, K. Evaluation of Thermal Environment in Vehicles for Occupant Comfort Using Equivalent Temperature of Thermal Manikin during Start-Stop Function with Energy Storage Evaporators. SAE Tech. Pap. Ser. 2018. [CrossRef]

32. Bolineni, S. Development of Reduced Order Flow Responsive Convection Heat Transfer Models for Human Body Segments in Multiple Applications; Lehrstuhl für Energieeffizientes Bauen: Aachen, Germany, 2017.

33. Rose, J. An approximate equation for the vapour-side heat-transfer coefficient for condensation on low-finned tubes. Int. J. Heat Mass Transf. 1994, 37, 865-875. [CrossRef]

34. Ferziger, J.H.; Peric, M. Computational Methods for Fluid Dynamics; Springer: Berlin, Germany, 1997.

35. Siemens, STARCCM+ Userguide, 2019. Available online: https://support.sw.siemens.com/ (accessed on 15 September 2020).

36. Siegel, R.H. Thermal Radiation Heat Transfer; Hemisphere Publishing Co.: Boulder, CO, USA, 1992.

37. Mathematische Nachbildung des Menschen—RAMSIS 3D-Softdummy, FAT-Bericht 135, Kaiserslautern, TECMAT GmbH; FAT-Bericht 135: Kaiserslautern, Germany, 1997.

38. van Treeck, C.; Mitterhofer, M. Temperaturfeldberechnung aus Einer Particle Image Velocimetry (PIV) Messung Einer Natürlichen Auftriebsströmung; Bauphysik: Aachen, Germany, 2013.

39. Tao, Z.; Cheng, Z.; Zhu, J.; Li, H. Effect of turbulence models on predicting convective heat transfer to hydrocarbon fuel at supercritical pressure. Chinese J. Aeronaut. 2016, 29, 1247-1261. [CrossRef]

40. Wilcox, D.C. Turbulence Modeling for CFD; DCW Industries: La Canada, CA, USA, 1989.

41. Menter, F.R. Two-equation eddy-viscosity turbulence modeling for engineering applications. AIAA J. 1994, 32, $1598-1605$. [CrossRef]

42. Atish, D.; Upender, G. A case study on human bio-heat transfer and thermal comfort within CFD. Build. Environ. 2015, 94, 122-130.

43. Thomschke, C.; Bader, V.; Gubalke, A.; van Treeck, C. Bewertung der transienten thermischen Behaglichkeit in einer realen Fahr-zeugumgebung, Human-centred building(s). In Proceedings of the 5th German-Austrian IBPSA Conference, BauSIM 2014, International Building Performance Simulation Association, German Speaking Chapter, Mainz, Germany, 22-24 September 2014.

44. Cook, M.; Yang, T. Cropper Thermal comfort in naturally ventilated classrooms: Application of coupled simulations models. In Proceedings of the Building Simulation, 12th Conference of International Building Performance Simulation Association, Sydney, Australia, 14-16 November 2011. 